\title{
Light-controlled inhibition of malignant glioma by opsin gene transfer
}

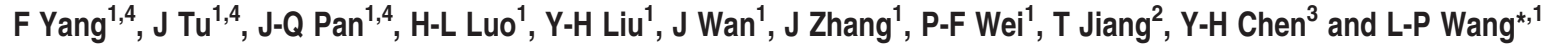

Glioblastomas are aggressive cancers with low survival rates and poor prognosis because of their highly proliferative and invasive capacity. In the current study, we describe a new optogenetic strategy that selectively inhibits glioma cells through light-controlled membrane depolarization and cell death. Transfer of the engineered opsin ChETA (engineered Channelrhodopsin-2 variant) gene into primary human glioma cells or cell lines, but not normal astrocytes, unexpectedly decreased cell proliferation and increased mitochondria-dependent apoptosis, upon light stimulation. These optogenetic effects were mediated by membrane depolarization-induced reductions in cyclin expression and mitochondrial transmembrane potential. Importantly, the ChETA gene transfer and light illumination in mice significantly inhibited subcutaneous and intracranial glioma growth and increased the survival of the animals bearing the glioma. These results uncover an unexpected effect of opsin ion channels on glioma cells and offer the opportunity for the first time to treat glioma using a light-controllable optogenetic approach.

Cell Death and Disease (2013) 4, e893; doi:10.1038/cddis.2013.425; published online 31 October 2013

Subject Category: Cancer

Primary central nervous system tumors account for $\sim 2.4 \%$ of all cancer deaths in the United States, ${ }^{1}$ among which human malignant glioma (MG) is one of the most common cancer types in adults. ${ }^{2}$ The high morbidity and mortality of MG are partially because of its high proliferative and invasive capacity. ${ }^{3}$ Understanding the regulation of the pathological activities of MG is important for eradicating it. ${ }^{4}$

Regulating polarization status of cell membrane and ion channels could exert effects on the activities of MG, including proliferation, migration, and metabolism. ${ }^{5-7}$ Blockage of the CIC3 channel, an anion channel for chloride, could inhibit DNA condensation and glioma cell division; ${ }^{8}$ Pharmacological inhibition of the Sodium-Potassium-Chloride Co-transporter could inhibit glioma cell division and decrease the glioma invasive capacity. ${ }^{8,9}$ Some evidence also suggests that $\mathrm{K}^{+}$ channels and membrane depolarization have an important role in regulating the death, growth, and migration of $M G$ cells. ${ }^{10-13}$ However, how MG cell ion transport and membrane depolarization influence signaling pathways controlling MG cell growth, proliferation, and death is unclear.

Optogenetic techniques can be used to achieve gain- or loss-of-function in a cell- or tissue-specific manner. ${ }^{14}$ By expressing channelrhodopsins ${ }^{15}$ or other opsin genes in individual cell types, the transport of ions and the depolarization of the cell membrane could be precisely controlled on a millisecond timescale by pulses of light illumination. ${ }^{16}$ Optogenetics has been widely used to interrogate neural circuits, ${ }^{17-25}$ regulate physiological activities including blood pressure and breathing, ${ }^{26-28}$ control intracellular signaling, ${ }^{29}$ and regulate the physiological function of astrocytes to activate neurons and trigger robust respiratory responses. ${ }^{30}$

On the basis of the important roles of ion transport and depolarization in regulating MG properties, we hypothesized that optogenetics could be used to modulate membrane depolarization and affect the activities of human MG. To achieve precise and versatile control of the membrane depolarization of glioma, we expressed the engineered opsin gene ChETA (engineered Channelrhodopsin-2 variant) ${ }^{31}$ in human glioma cells. We found that light stimulation could regulate their membrane depolarization and decrease their viability, and the inhibition of glioma cell proliferation and induction of apoptosis could be precisely controlled by visible light in a tissue-specific manner. Our study not only demonstrates for the first time how light-controlled membrane depolarization influences human MG properties including proliferation and death but also provides a new

\footnotetext{
${ }^{1}$ Shenzhen Key Lab of Neuropsychiatric Modulation, Research Centre for Neural Engineering, Shenzhen Institutes of Advanced Technology, Chinese Academy of Sciences, Xili Nanshan, Shenzhen, China; ${ }^{2}$ Department of Neurosurgery, Beijing Tiantan Hospital, Capital Medical University, Beijing, China and ${ }^{3}$ Department of Pathology and Laboratory Medicine, School of Medicine, University of Pennsylvania, Philadelphia, PA, USA

${ }^{*}$ Corresponding author: L-P Wang, Research Centre for Neural Engineering, Key Laboratory for Health Informatics at Shenzhen Institutes of Advanced Technology, Chinese Academy of Sciences, Xili Nanshan, 1068 Xueyuan Boulevard University Town of Shenzhen, Shenzhen 518055, China. Tel: +86 755 86392218 ; Fax: +86 755 86392233; E-mail: Ip.wang@ @iat.ac.cn

${ }^{4}$ These authors contributed equally to this work.

Keywords: gene therapy; cancer; channelrhodopsin; optogenetic; glioma

Abbreviations: BSA, bovine serum albumin; ChETA, engineered Channelrhodopsin-2 variant; DMEM, Dulbecco's Modified Eagle Medium; eYFP, enhanced yellow fluorescence protein; EdU, 5-Ethynyl-2-deoxyuridine; GFAP, glial fibrillary acidic protein; HE, hematoxylin and eosin; HEPES, 4-(2-hydroxyethyl)-1piperazineethanesulfonic acid; Iba1, ionized calcium-binding adaptor molecule 1; LED, light-emitting diode; MG, malignant glioma; MTT, 3-(4,5-dimethylthiazol-2-yl)2,5-diphenyltetrazolium bromide; PBS, phosphate buffered saline; PI, propidium iodide; PFA, paraformaldehyde; TRPC, transient receptor potential canonical channel; TUNEL, deoxynucleotidyl transferase (TdT)-mediated dUTP nick end labeling

Received 13.7.13; revised 19.9.13; accepted 20.9.13; Edited by A Stephanou
} 
approach to inhibit the growth of human glioma through controllable visible light.

\section{Results}

The opsin ChETA expression and light stimulation selectively reduced the viability of human glioma cells. To determine whether the viability of cultured neurons, astrocytes, and human glioma cells could be influenced by optogenetic manipulation (Figures 1a-e), we used a lentivirus carrying the CMV-ChETA-eYFP construct (Figure 1a) to transfect the rat brain-derived normal neurons, astrocytes, and human U87 and H4 glioma cell lines. Forty-eight hours after the transfection, most of the neurons, astrocytes, and U87/H4 cells were successfully labeled, expressing the green fluorescence (Figure 1b). We constructed a blue light-emitting diode (LED) (Figure 1c) and illuminated the transfected cells with it for $1 \mathrm{~h}$ (Figure 1d). Twenty-four hours after the light stimulation, cell viability was evaluated using the 3-(4,5-dimethylthiazol-2-yl)-2,5-diphenyltetrazolium bromide (MTT) assay. As expected, ChETA + light treatment did not affect the viability of normal neurons and astrocytes (Figure 1e), as well as endothelial cells and microglia (Supplementary Figures S2A and B). By contrast, the viability of U87 and $\mathrm{H} 4$ glioma cells treated with ChETA + light was reduced to $56.3 \pm 5.9 \%$ and $50.4 \pm 4.6 \%$, respectively significantly lower than that of the control groups $(P<0.01)$ (Figure 1e). The light-induced decrease in cell viability was also observed in U251 and Ai72 glioma cells (Supplementary Figure S2C), but not in other cancer cell lines (MDA231, Hela, HepaG2) (Supplementary Figure S2D), suggesting that light stimulation selectively decreased the viability of ChETAexpressing glioma cells.

To selectively target glioma cells, we constructed a lentivirus carrying the c-fos-ChETA-eYFP construct (Figure 1a), based on the finding that tumor, but not normal cells, expresses high levels of the c-fos. ${ }^{31,32}$ Forty-eight hours after the transfection, $>98 \%$ of the $\mathrm{U} 87$ and $\mathrm{H} 4$ cells showed the green fluorescence, which concentrated on the plasma membrane (Figure 1f, Supplementary Figure S2E), whereas no such fluorescence was observed in the astrocytes (Figure 1f). We then used patch-clamp techniques to investigate the function of ChETA in U87 glioma cells (Figures 1g-I, Supplementary Figure S1). Stimulating ChETA-expressing glioma cells with blue light $(450-490 \mathrm{~nm})$ for $500 \mathrm{~ms}$ induced depolarizing currents (Figure 1h) with a peak amplitude at $420.2 \pm 103.7 \mathrm{pA}$ and a steady-state amplitude at $394.3 \pm 98.8 \mathrm{pA}$ (mean \pm S.E.M., Figure 1i; $n=12$ ). We used single light pulse durations of $1,21,51$, 101, and $201 \mathrm{~ms}$ to stimulate the glioma cells (Figure 1j); $51 \mathrm{~ms}$ of light illumination was sufficient to induce a depolarizing peak and a steady state (Figure 1j). Paired light stimuli (50 ms of illumination) with intervals of $25,50,75,100$, and $200 \mathrm{~ms}$ were also used to stimulate the glioma cells (Figure 1k); paired stimuli with a time interval of $50 \mathrm{~ms}$ or above could allow the full recovery from the first light-induced spike (Figure 1k). We then continuously illuminated the ChETA-expressing glioma cells for $1 \mathrm{~h}(50 \mathrm{~ms}$ of $10-\mathrm{Hz}$ illumination), after which, ChETA spike trains could be successfully induced (Figure 1I). Taken together, the electrophysiological recordings showed that the light stimulation protocol we used (10 Hz and $50-m s$ stimulus intervals) was sufficient and stable to induce the membrane depolarization of the ChETA-expressing human glioma cells.

To exclude nonspecific effects of ChETA expression or light stimulation, we added control, light only, eYFP + light (using cfos-eYFP lentiviral vector), and ChETA groups (Figures $2 \mathrm{a}-\mathrm{c}$ ). Twenty-four hours after the light stimulation of the glioma cells, we observed a significantly reduced crystal violet staining of U87 cells in the ChETA + light group compared with the control, light, eYFP + light, and ChETA groups (Figure 2a, Supplementary Figure S2F). MTT assay showed that U87 cell viability in the ChETA + light group was $46.8 \pm 5.8 \%$, significantly lower than that in both the control group $(P<0.001)$ and the ChETA group $(P<0.01)$ (Figure 2b). $\mathrm{H} 4$ cell viability in the ChETA + light group was $29.7 \pm 3.7 \%$, significantly lower than that in both the control group $(P<0.001)$ and the ChETA group $(P<0.05)$ (Figure 2c).

We next investigated the effect of our optogenetic procedure on primary glioma cells of patients. The glioma cells were isolated from four patients with different pathological grading (Figure 2d). A high proportion of the glioma cells isolated from patients 1, 2, and 3 expressed GFAP and nestin, confirming the astroglial origin of the primary cultured cells (Figure $2 \mathrm{e}$ ). Five days after transfection, $>70 \%$ percent of the glioma cells (isolated from patients 1, 2, and 3) showed the green fluorescence (Figure 2f), whereas no green fluorescence was observed in cells isolated from patient 5 who had no glioma (Figure 2f). Electrophysiological recordings showed that stimulating ChETA-expressing primary glioma cells with blue light for $500 \mathrm{~ms}$ induced depolarizing currents (Figures $2 \mathrm{~g}$ and $h$ ); spike trains were also successfully induced by light stimulations with $10 \mathrm{~Hz}$ at 50 -ms stimulus intervals (Figure 2i). Twenty-four hours after the light stimulation, MTT assay showed that the viability of cells from patients 1 to 4 of the ChETA + light group was $46.6 \pm 4.9 \%, 57.9 \pm 3.2 \%$, $52.7 \pm 3.2 \%$, and $54.6 \pm 3.0 \%$, respectively, significantly lower than those of the control group $(P<0.001)$, light group $(P<0.05)$, and the ChETA group $(P<0.05)$ (Figure 2j).

ChETA optogenetic treatment inhibited cell cycle progression and proliferation of human glioma cells. We then investigated the mechanism of decreased viability of ChETA-expressing glioma cells after light stimulation. Cell cycle analysis using flow cytometry showed that the cell cycle progression in the ChETA + light group became disrupted: the fraction of cells in the G2/M (4n) phase decreased compared with control, light, and eYFP + light groups, and the fraction in the pre-Go $(<2 n)$ phase increased compared with the other four groups (Figure 3a), suggesting decreased glioma cell proliferation and increased cell death after the light stimulation.

Next, we investigated whether light illumination could inhibit the proliferation of glioma cells at $24 \mathrm{~h}$ after the light stimulation using the 5-ethynyl-2-deoxyuridine (EdU) incorporation assay (Figures $3 b$ and $c$ ). There were less EdUpositive cells (green) in the ChETA + light group compared with other groups (Figure $3 b$ ), and quantification showed that the percentage of EdU-positive cells in the ChETA + light 
a
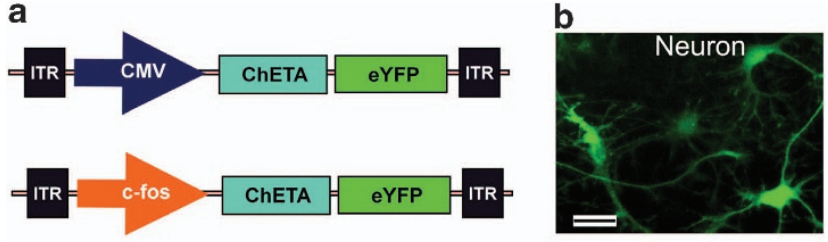

C

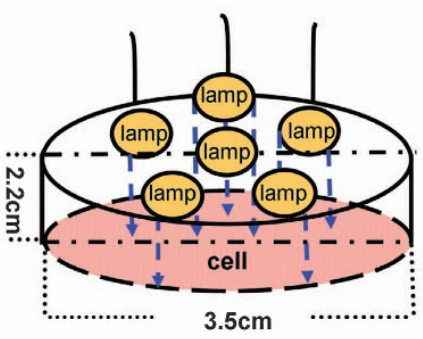

d

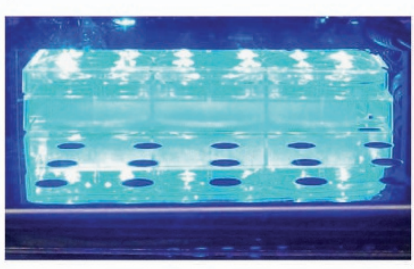

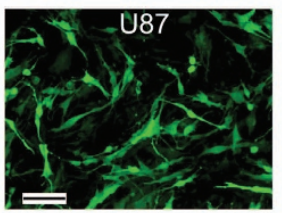
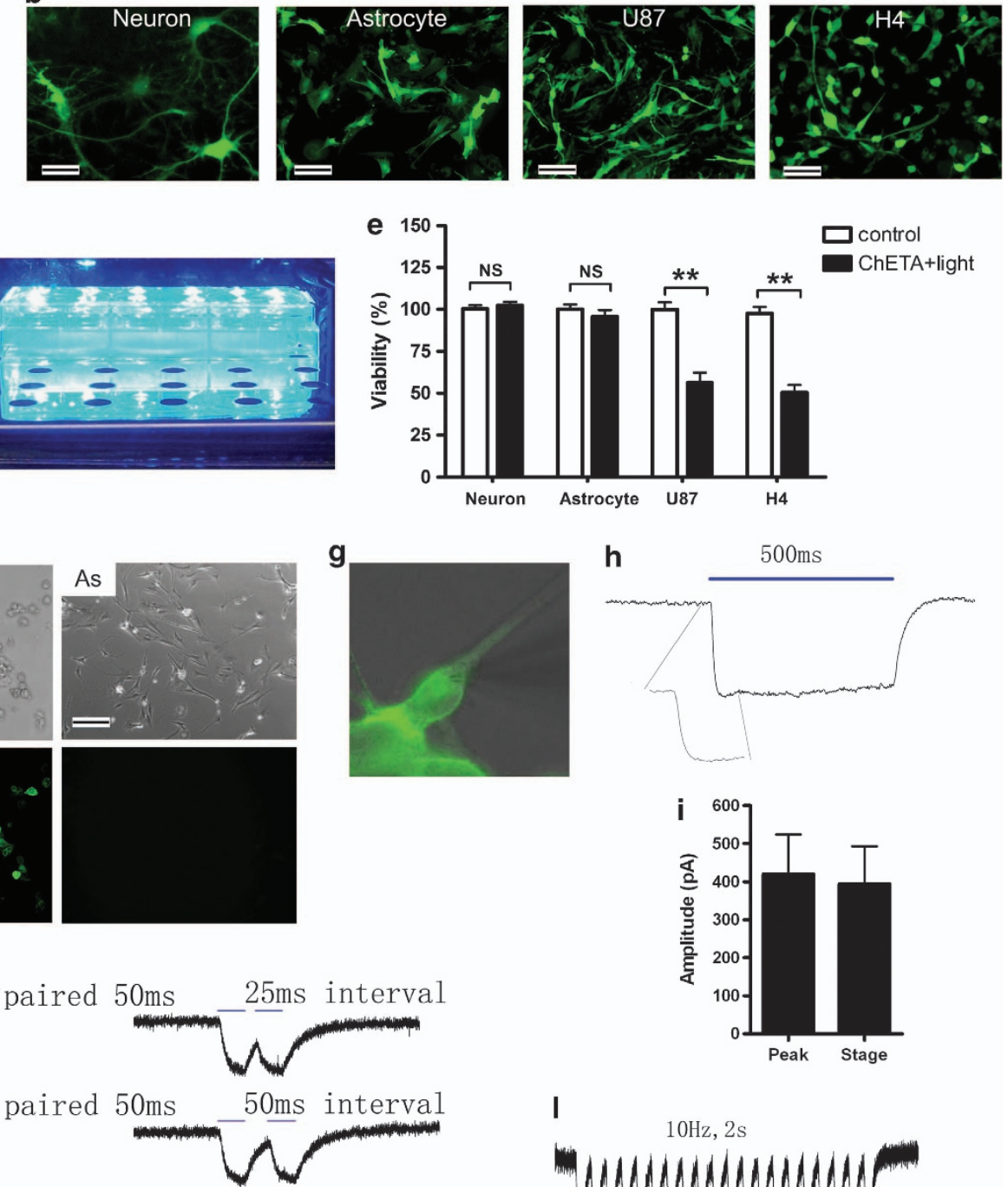

paired $50 \mathrm{~ms}$

$75 \mathrm{~ms}$ interval

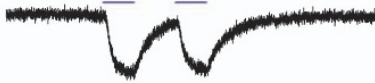

$101 \mathrm{~ms}$
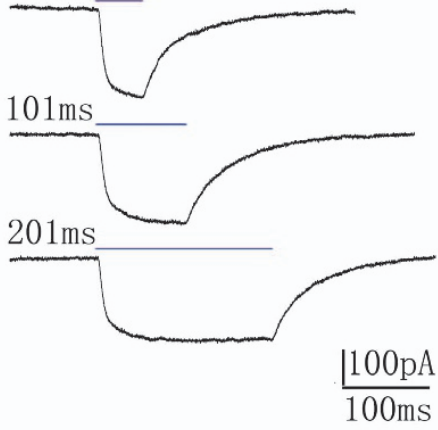

paired $50 \mathrm{~ms}$

$100 \mathrm{~ms}$ interval

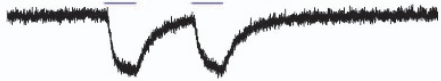

paired $50 \mathrm{~ms}$

$200 \mathrm{~ms}$ interval

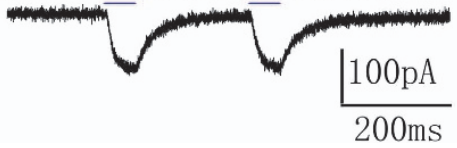

I

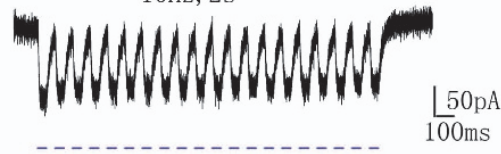

Before 1h light flashing

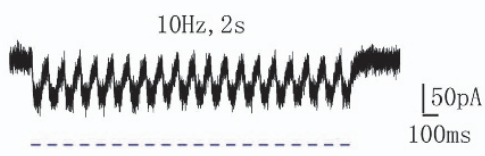

After 1h light flashing

Figure 1 ChETA gene transfer and electrophysiological recordings of human glioma cells. (a) Schematic drawings of the CMV-ChETA-eYFP and cfos-ChETA-eYFP lentivirus vector constructs. (b) Positive ChETA expression (green) was observed in normal neurons, astrocytes, and U87/H4 glioma cell lines transfected with CMV-ChETA-eYFP lentivirus. Bar $=20 \mu \mathrm{m}$. (c) Schematic drawing of the arrangement of the lamps in the blue LED constructed for the light illumination; the average light intensity was $1.64 \mathrm{~mW} / \mathrm{mm}^{2}$. (d) The constructed blue LED used to illuminate the cells in six-well plates. (e) Quantification of the percentage of viable neurons, astrocytes, and $\mathrm{U} 87 / \mathrm{H} 4$ cells in the control and ChETA + light groups. (f) Positive ChETA expression was seen in the U87 and $\mathrm{H} 4$ glioma cells but not in rat astrocytes (As) transfected with cfos-ChETA-eYFP lentivirus; bar $=50 \mu \mathrm{m}$. Top panel: bright field; bottom panel: ChETA expression (shown in green). (g) Whole-cell patch clamping was used to record light-evoked photocurrents from ChETA-expressing U87 cells. (h) Light stimulation (500 ms) induced depolarization and a recovery current. (i) The peak and steady-state amplitude of the induced depolarization current, $n=12$. (j) A ChETA channel current spike was induced by 1-, 21-, 51-, 101-, and 201-ms-light pulses. (k) Spike trains induced by paired light stimulations with 25-, 50-, 75-, 100-, and 200-ms intervals. (I) Spike trains were induced before (top panel) and after $1 \mathrm{~h}$ (bottom panel) of light illumination $(10 \mathrm{~Hz}) .{ }^{* \star} P<0.01$ 


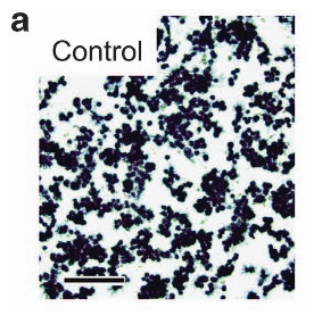

b

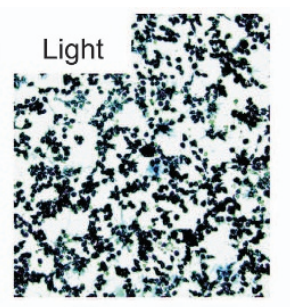

U87

Cell viability (MTT)

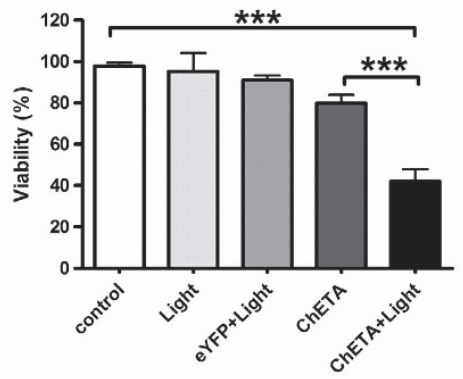

d

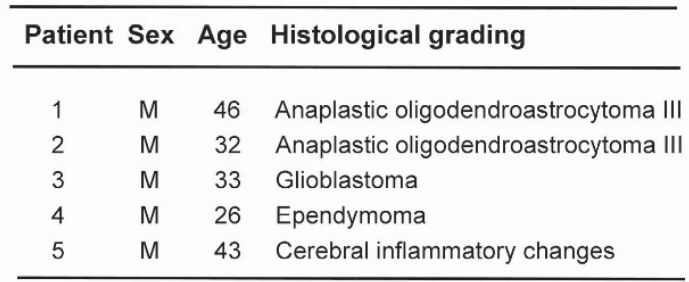

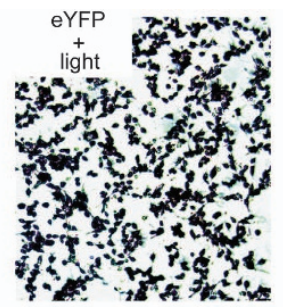

C
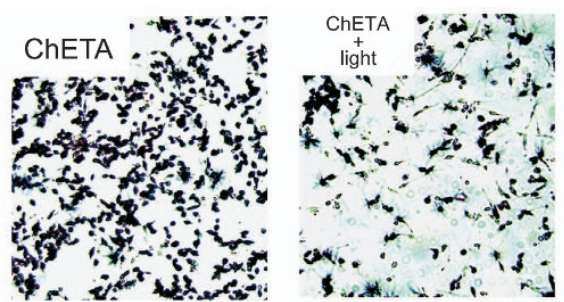

H4

Cell viability (MTT)

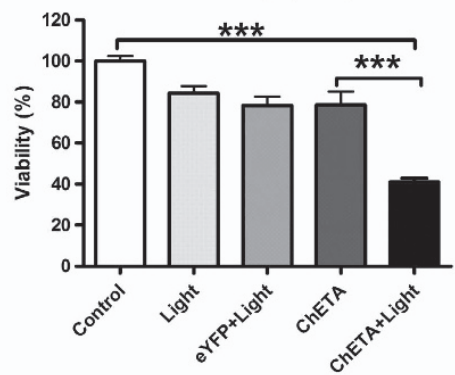

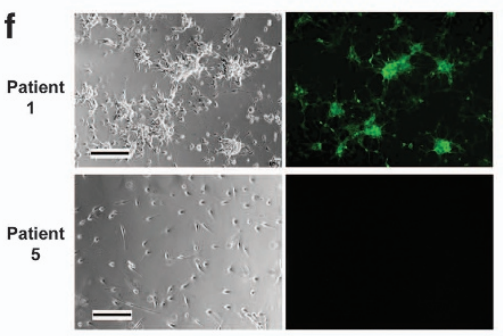
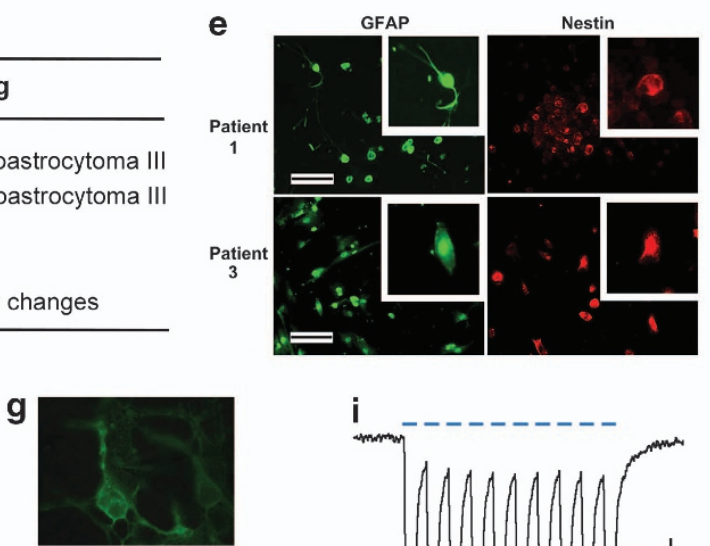

h
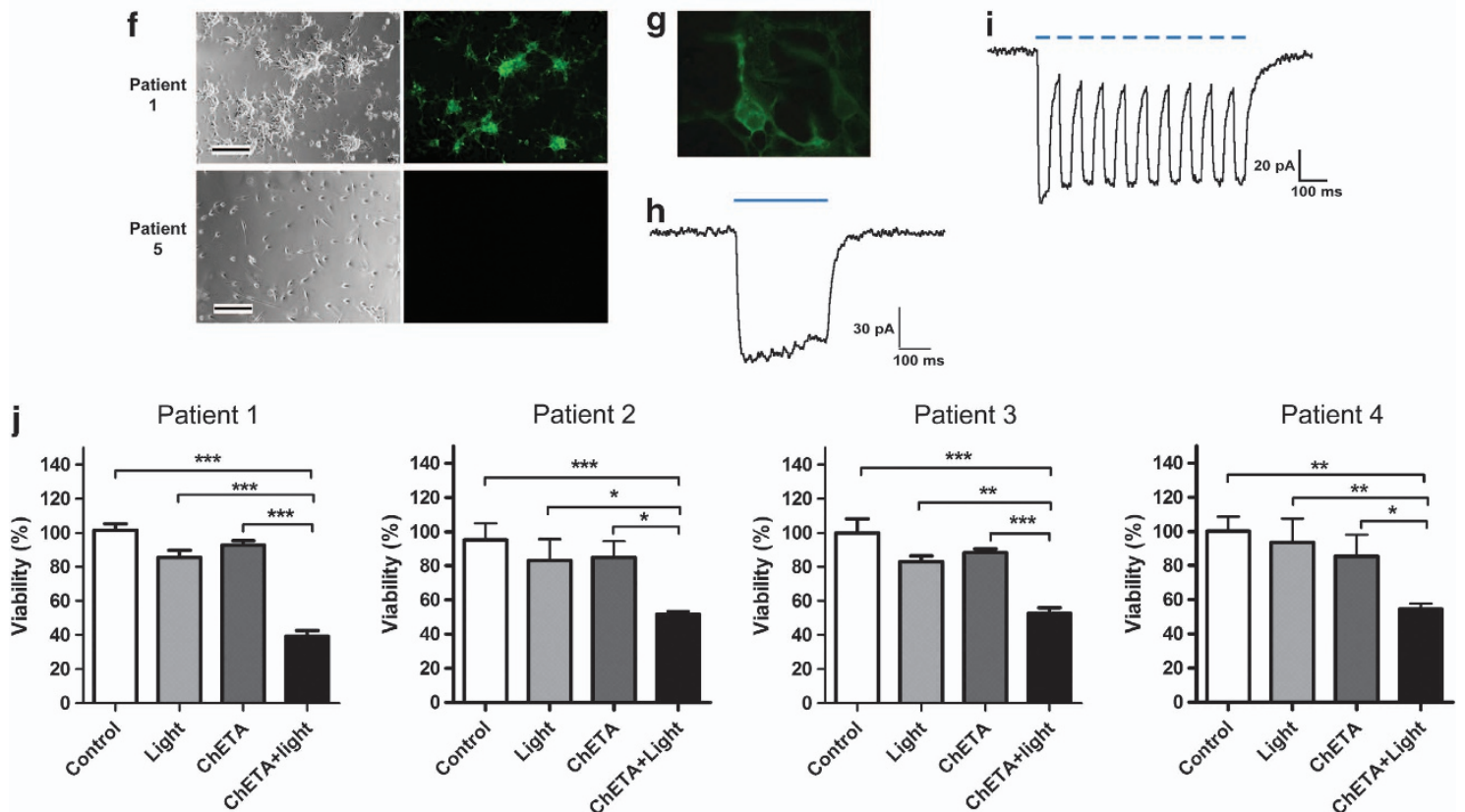

Figure 2 ChETA gene expression and light stimulation reduced the viability of human glioma cells. (a) Crystal violet staining of the viable U87 cells $24 \mathrm{~h}$ after light stimulation; bar $=100 \mu \mathrm{m}$. (b) Quantification of the viability of U87 cells in the indicated groups $(n=15)$. (c) Quantification of the viability of $\mathrm{H} 4$ cells in the indicated groups $(n=15)$. (d) Sex, age, and histological grading of the patients used for primary neural cell isolation and culture. (e) Immunofluorescence of GFAP and nestin on cultured primary human glioma cells (patients 1 and 3 ); bar $=50 \mu \mathrm{m}$. (f) Representative ChETA expression in primary cultured human glioma cells (patient 1 , right panel). No expression was observed in cells isolated from patient 5 who had no glioma; bars $=50 \mu \mathrm{m}$. (g) A whole-cell patch clamp was used to record light-evoked photocurrents from representative ChETA-expressing primary human glioma cells (patient 1). (h) Light stimulation (500 ms) induced depolarization and the recovery current. (i) ChETA channel current spike trains induced by light pulses $(50 \mathrm{~ms}, 10 \mathrm{~Hz}$ ). (j) Quantification of primary human glioma cell viability in the control, light, ChETA, and ChETA + light groups isolated from patients $1-4$, respectively. $n=16$. ${ }^{\star} P<0.05$; ${ }^{\star \star} P<0.01$; ${ }^{\star \star \star} P<0.001$ 

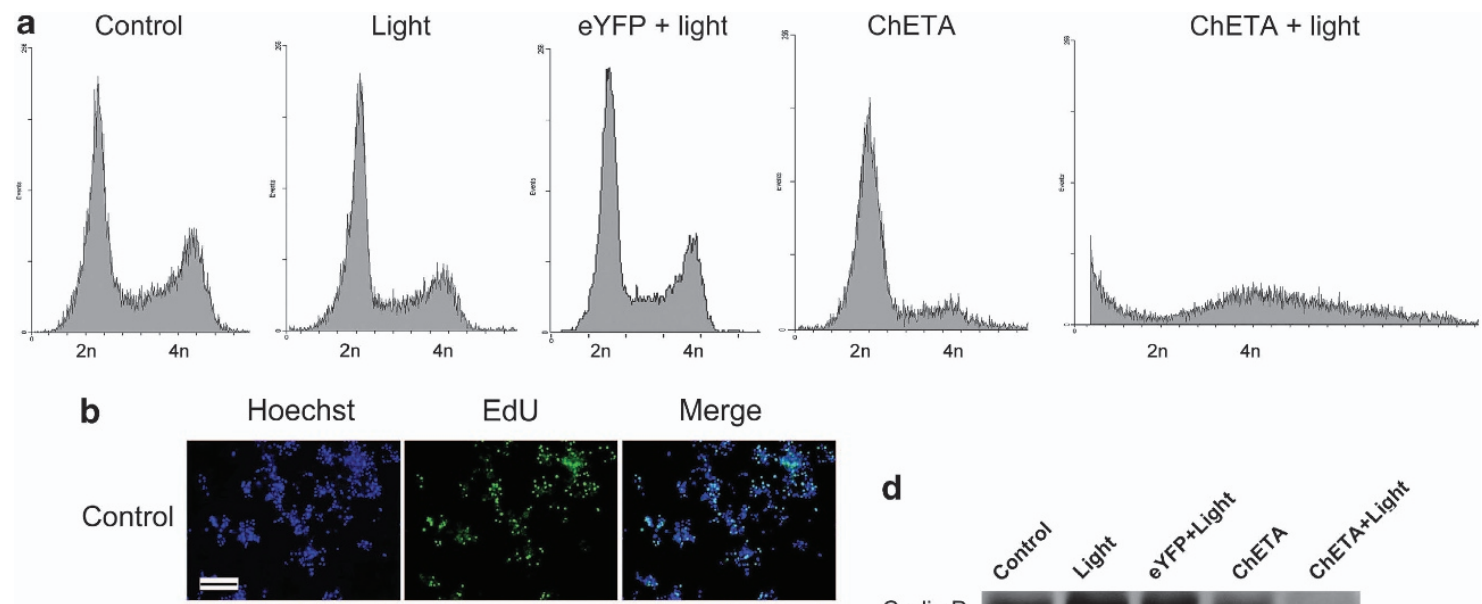

Merge
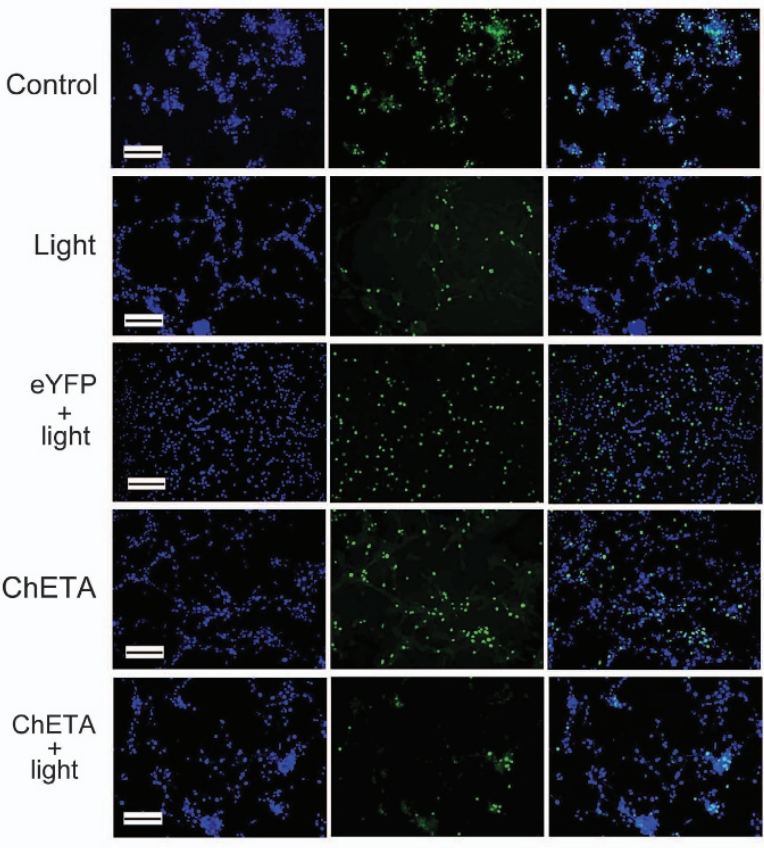

d
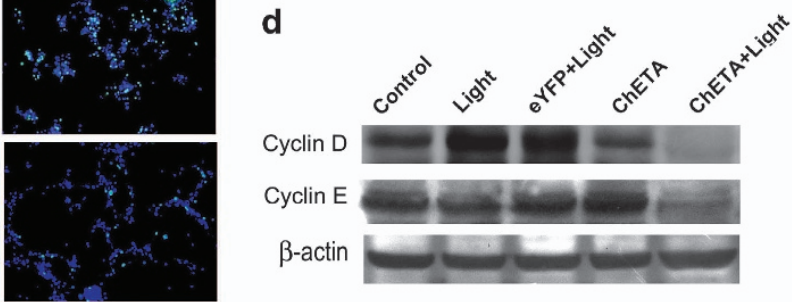

Cyclin D

Cyclin E

$\beta$-actin

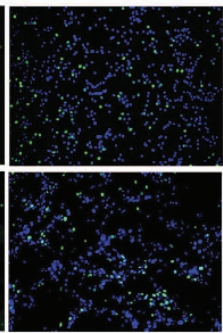

e
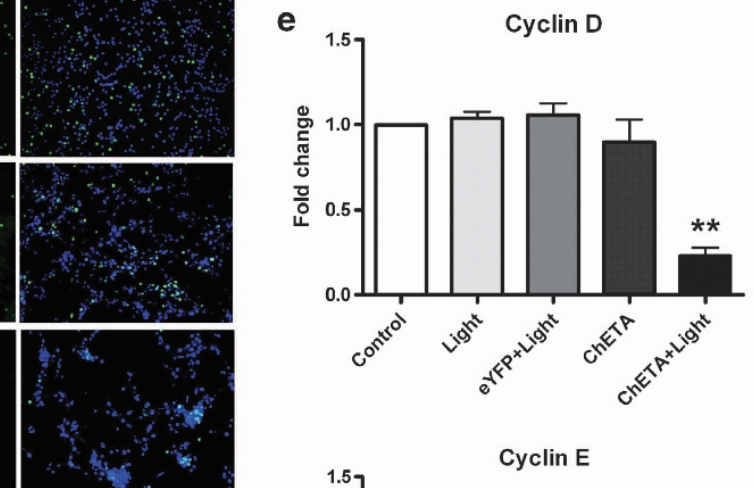

Cyclin E
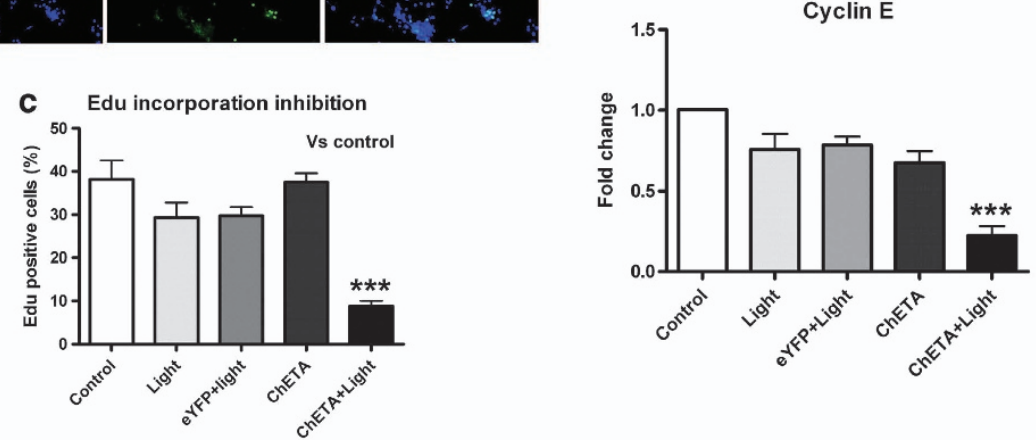

Figure 3 Light stimulation inhibited the proliferation of human glioma cells. (a) Cell cycle analysis of U 87 cells in the control, light, eYFP + light, ChETA, and ChETA + light groups $24 \mathrm{~h}$ after light stimulation. (b) Green-fluorescent EDU-incorporated cells were observed in the control, light, eYFP + light, ChETA, and ChETA + light groups at $24 \mathrm{~h}$ after the light stimulation. Hoechst 33342-stained nuclei are shown in blue; bar $=100 \mu \mathrm{m}$. (c) Quantification of the percentage of EdU-positive cells in the control, light, eYFP + light, ChETA, and ChETA + light groups, $n=8$. (d) Western blot analysis of $\beta$-actin, cyclin D, and cyclin E protein expression in the control, light, eYFP + light, ChETA, and ChETA + light groups at $24 \mathrm{~h}$ after the light stimulation. (e) Quantification of cyclin D and cyclin E protein expression in the control, light, eYFP + light, ChETA, and ChETA + light groups. $n=3 .{ }^{* \star} P<0.01 ;{ }^{* \star} P<0.001$

group $(8.76 \pm 1.25 \%)$ was significantly lower than that of the control group (38.15 $\pm 4.41 \%$ ) (Figure $3 c$ ).

Western blotting was used to investigate the expression of cyclin D1 and cyclin E in stimulated glioma cells at $24 \mathrm{~h}$ after the light stimulation (Figure $3 d$ ). The expression levels of cyclin D1 and cyclin E were downregulated in the ChETA + light group, and quantification showed that the difference in expression between the ChETA + light and control groups was significant for both cyclin $\mathrm{D} 1(P<0.01)$ and cyclin $\mathrm{E}(P<0.001)$ (Figure 3e).
Light stimulation induced mitochondria-dependent apoptosis of human glioma cells. Propidium iodide (PI) staining of glioma cells was used to confirm the glioma cell death induced by light. There were more PI-positive cells (red) in the ChETA + light group (Figure 4a), and quantification showed that the percentage of $\mathrm{PI}$-positive cells in the ChETA + light group was significantly higher than that in the control $(P<0.001)$ and ChETA $(P<0.01)$ groups (Figure 4b). 
a
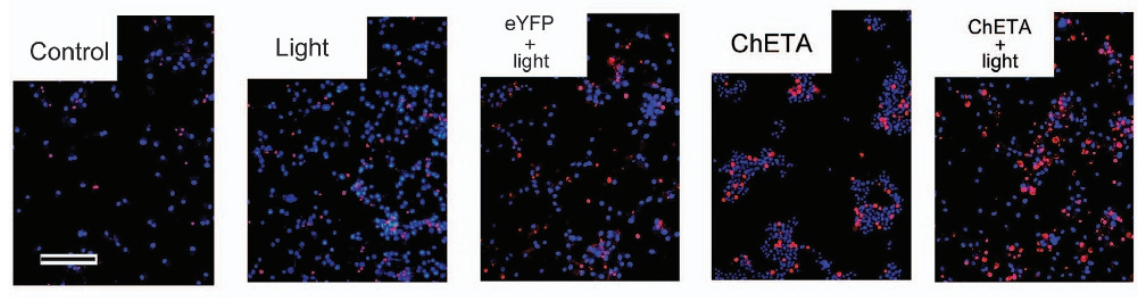

C
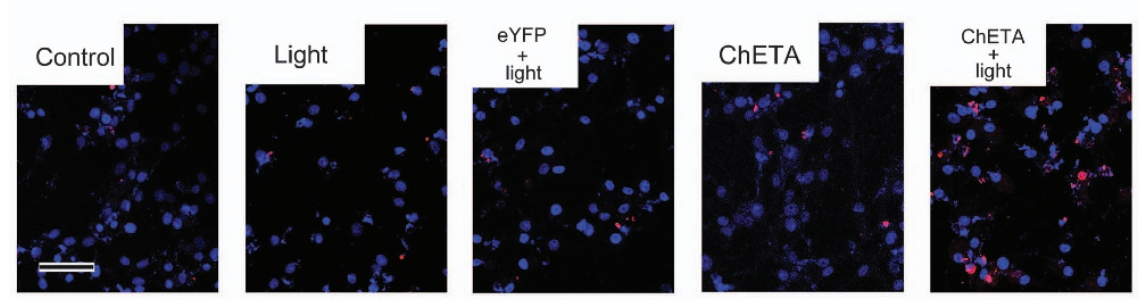

b

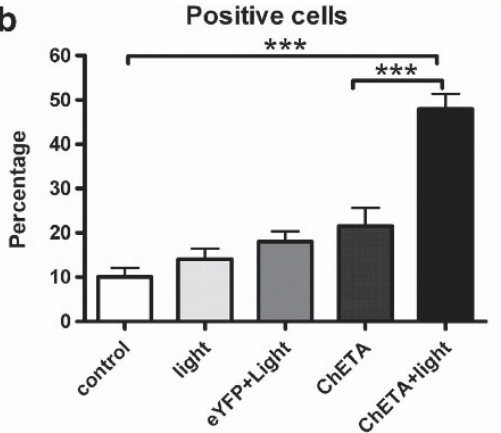

d
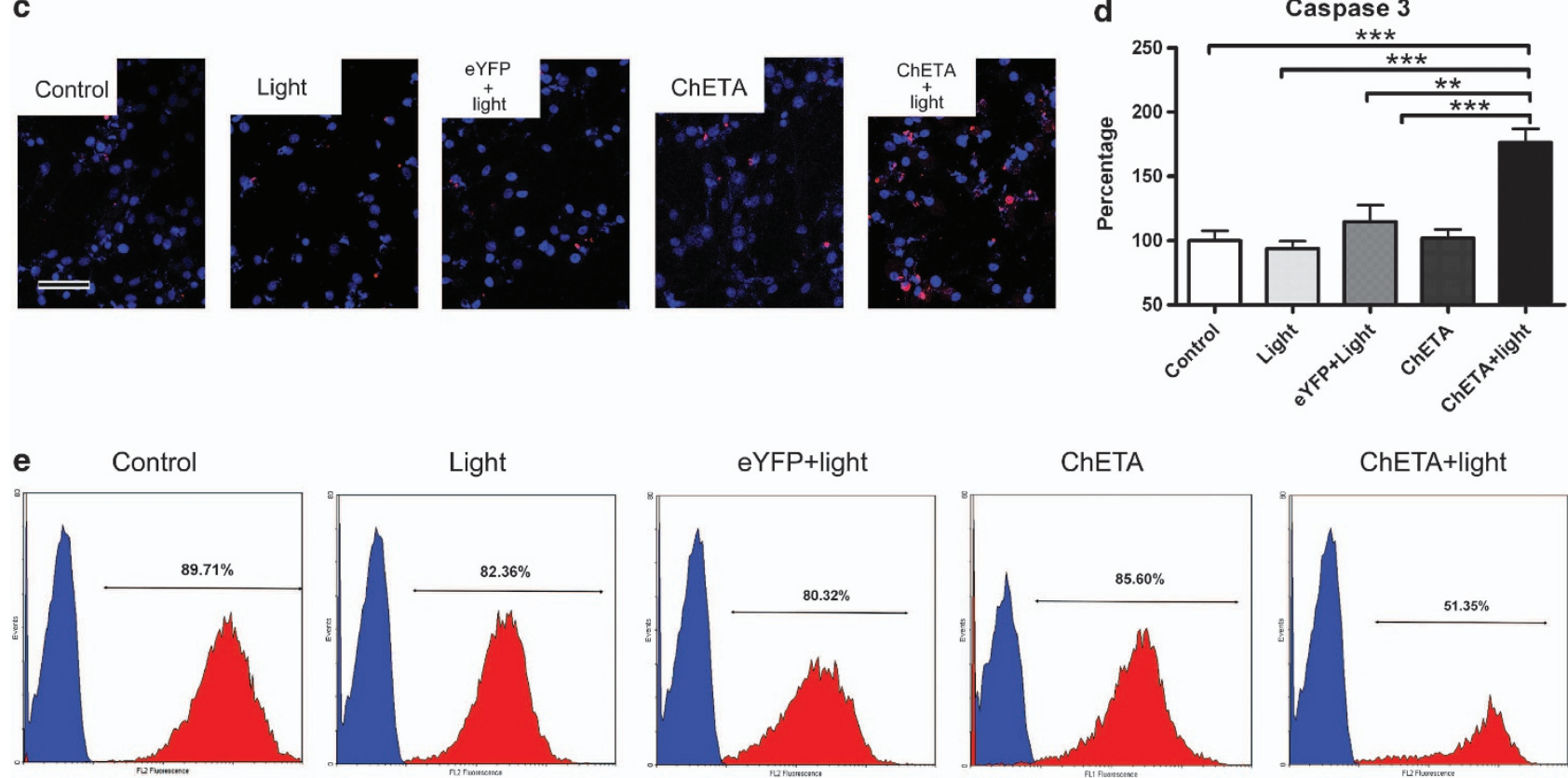

f Loss of membrane potential $\left(\Delta \psi_{m}\right)$

Cytochrome C

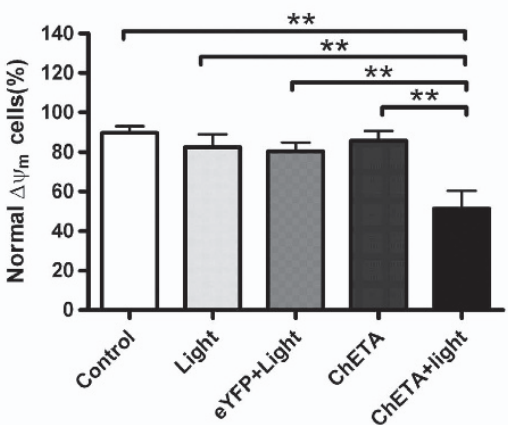

g

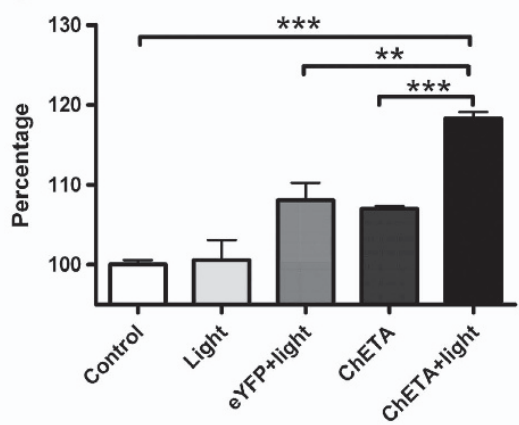

h

Cell Viability (ChETA+light)

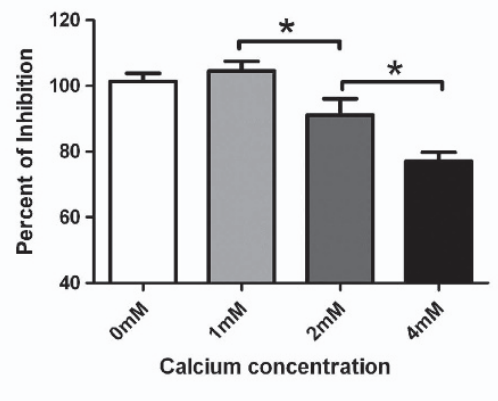

Figure 4 Light stimulation induced the mitochondria-dependent apoptosis of human glioma cells. (a) PI-stained U87 cells in the control, light, eYFP + light, ChETA, and ChETA + light groups are shown in red, and Hoechst 33342-stained nuclei are shown in blue. Bar $=100 \mu \mathrm{m}$. (b) Quantification of the PI-positive cells in the control, light, eYFP + light, ChETA, and ChETA + light groups, $n=5$. (c) TUNEL staining of apoptotic U87 cells in the control, light, eYFP + light, ChETA, and ChETA + light groups (shown in red). Hoechst 33342-stained nuclei are shown in blue; bar $=50 \mu \mathrm{m}$. (d) Quantification of human active Caspase 3 in the control, light, eYFP + light, ChETA, and ChETA + light groups. $n=3$. (e) Flow cytometric analysis of mitochondrial membrane potential in the control, light, eYFP + light, ChETA, and ChETA + light groups. (f) Quantification of the percentage of glioma cells with normal membrane potential in the control, light, eYFP + light, ChETA, and ChETA + light groups. $n=3$. (g) Quantification of cytosolic cytochrome $c$ in the control, light, eYFP + light, ChETA, and ChETA + light groups. $n=6$. (h) Quantification of the percentage of viable U87 at different extracellular calcium concentrations. ${ }^{*} P<0.05 ;{ }^{\star *} P<0.01 ;{ }^{* \star *} P<0.001 . n=10$

Then, we asked whether ChETA expression and light stimulation could promote mitochondria-dependent apoptotic signaling in glioma cells. Firstly, terminal deoxynucleotidyl transferase (TdT)-mediated dUTP nick end labeling (TUNEL) staining showed that there were more positive cells (red) in the ChETA + light group than those in the other groups 
(Figure 4c), and there were few positive signals on neurons, astrocytes, microglia, and endothelial cells (Supplementary Figure S3A); the level of human active Caspase-3 in glioma cells also significantly increased in the ChETA + light group compared with other groups $(P<0.001$, Figure $4 d)$. The changes of mitochondrial membrane potential were then analyzed using flow cytometry, and we observed significantly decreased percentage of glioma cells with normal mitochondrial membrane potential in ChETA + light group (Figure 4e). Quantification showed that the percentage of glioma cells with normal membrane potential in the ChETA + light group $(51.35 \pm 8.89 \%)$ was significantly lower than those of the control, light, eYFP + light, and ChETA groups $(P<0.01)$ (Figure 4f).

Mitochondrial membrane potential regulates the release of cytochrome $c$ during apoptosis. ${ }^{33}$ We quantified cytosolic cytochrome $c$ and found a significant increase in the ChETA + light group compared with other groups $(P<0.01)$ (Figure $4 \mathrm{~g})$. We also found that increasing the extracellular $\mathrm{Ca}^{2+}$ concentration significantly enhanced the inhibitory effects of light stimulation on the viability of glioma cells (Figure $4 \mathrm{~h}$ ). Taken together, these data suggested that light-controlled membrane depolarization could induce the mitochondriamediated apoptosis of human glioma cells.

Growth of subcutaneous glioma in mice was markedly inhibited by ChETA expression and light stimulation. In order to determine the therapeutic effect of our optogenetic strategy in vivo, the subcutaneous glioma model was established through implantation of U87 cells in mice (Figure 5a). Hematoxylin and eosin (HE) staining and GFAP immunostaining were used to mark the tumor tissue (Figure 5b). Positive eYFP expression was observed 1 week after the injection of the cfos-ChETA-eYFP lentivirus into the ChETA group (Figure $5 \mathrm{c}$ ), and $>70 \%$ of the glioma cells showed green fluorescence in the ChETA group (Figure $5 \mathrm{c}$ ). A blue light illumination device was used (Figure $5 \mathrm{~d}$ ) to illuminate the subcutaneous glioma for $30 \mathrm{~min}$ (Figure 5e). At 2 weeks after the blue light illumination, the tumor sizes in the control, light, eYFP + light, ChETA, and ChETA + light groups became 241.1 $\pm 20.3,225.9 \pm 21.8,207.5 \pm 12$, $229.2 \pm 17.5$, and $84.2 \pm 17.8 \mathrm{~mm}^{3}$, respectively (mean \pm S.E.M.; $n=5$ ) (Figure 5f). The tumor sizes in the ChETA+ light group decreased significantly compared with those in the other four groups both 2 and 4 weeks after the light stimulation $(P<0.01)$. Upon excision, tumors of the ChETA + light group were notably smaller than those in the control, light, eYFP + light, and ChETA groups (Figure 5g; $n=3$ in each group) at 2 weeks after the light stimulation.

$\mathrm{HE}$ staining of tumors in the control, light, eYFP + light, and ChETA groups showed typical histological features of glioma, including high cellular density and an infiltrative growth pattern (Figure 5h); however, in the ChETA + light group, necrotic foci were observed, the tissue alignment became irregular, and glioma cellular density decreased significantly compared with the other four groups (Figure 5h). Cyclin D1 immunostaining showed that strong signals (brown) were observed around glioma cells in the control, light, eYFP + light, and ChETA groups; however, the signals of Cyclin D1 significantly decreased in the ChETA + light group (Figure 5i).
Intracranial glioma growth in mice was significantly inhibited by ChETA expression and light stimulation. In order to further investigate the effect of our optogenetic therapy on in situ glioma growth, we next transplanted CMVChETA-transfected U87 glioma cells or normal astrocytes into the striatum region of nude mice (Figure 6a). A blue lightemitting optical fiber was used to illuminate the intracranial region (Figure $6 \mathrm{~b}$ ) for $30 \mathrm{~min}$. At 1 week after the light stimulation, we observed no significant changes in greenfluorescence distribution of normal astrocytes (Figure 6d); however, for U87 glioma cells, the area of greenfluorescence distribution in the ChETA + light group significantly decreased compared with that in the control group (Figure 6d).

We then systemically investigated the optogenetic effects on the intracranial glioma (Figures $6 e$ and f). At 1 week after injecting the cfos-ChETA-eYFP lentivirus into the glioma region, strong eYFP signals were observed in the ChETA group (Figure $6 \mathrm{~g}$ ). Quantification showed that $>80 \%$ of the intracranial glioma cells were labeled with green fluorescence, whereas no green-fluorescent cells were observed in the control group (Figure 6h). The colocalization of ChETA-eYFP and GFAP showed that ChETA expression (green) was mainly restricted to the tumor region, whereas very few greenfluorescent cells were observed outside the tumor region, suggesting the specific expression of ChETA in the intracranial glioma (Figure 6i).

To further assess the therapeutic effect of the optogenetic treatment, we monitored the survival of nude mice bearing intracranial glioma. We found that mice in the ChETA + light group had significantly longer survival times (mean $=62$ days; $P<0.05)$ compared with glioma-bearing mice in the control (mean $=45$ days), light (mean $=49$ days), eYFP + light (mean $=46$ days), or ChETA (mean $=47$ days) groups ( $n=6$ in each group) (Figure $6 \mathrm{j}$ ). HE staining performed 2 weeks after the light stimulation showed that the tumor size had decreased significantly in the ChETA + light group compared with the other four groups (Figure 6k). The tumor structure in the ChETA + light group became disorganized, the cellular density decreased, and necrotic foci became apparent (Figure 6k, HE $\times 40$ ).

Furthermore, immunofluorescence showed that the number of nestin-positive cells in the ChETA + light group decreased significantly compared with those in the other groups (Figure 7a, Supplementary Figure S3C). The EdU incorporation assay suggested that the number of in vivo dividing glioma cells were significantly decreased in the ChETA + light group compared with the other four groups (Figure 7b, Supplementary Figure S3D). The expression of cyclin D1 was also significantly inhibited in ChETA + light group by light stimulation (Figure 7c). To test the apoptosis of intracranial glioma cells, we performed TUNEL staining and found that there were more apoptotic cells in the ChETA+ light group than in the other groups (Figure 7d); quantification showed that the percentage of TUNEL-positive cells in the ChETA + light group was $21.57 \pm 2.3 \%$ (mean \pm S.E.M.; Figure $7 e ; n=10)$, significantly higher than those in the other four groups $(P<0.001)$. Taken together, the downregulated expression of cyclin $D$ and nestin, decreased number of dividing glioma cells, and increased number of 

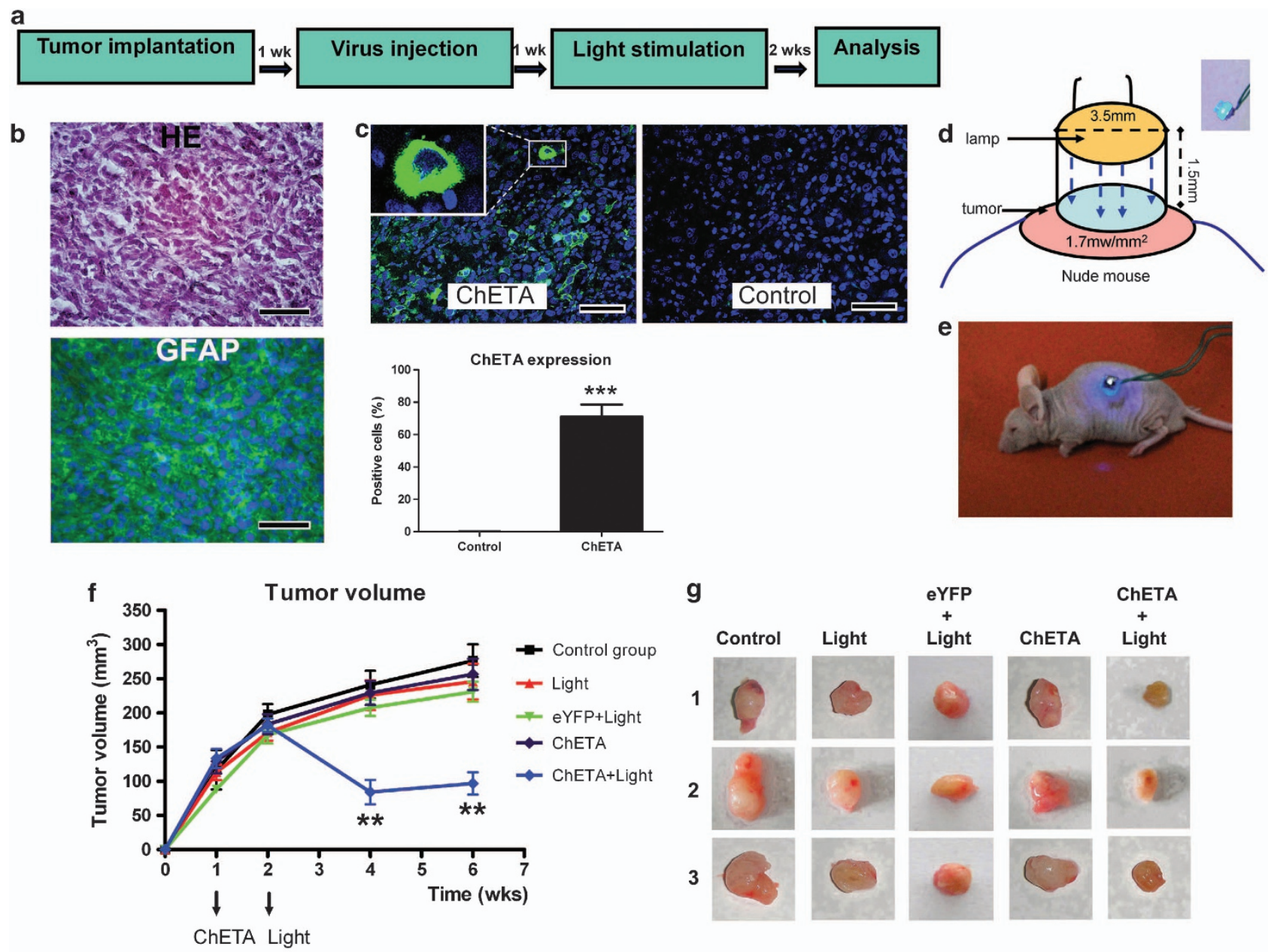

g

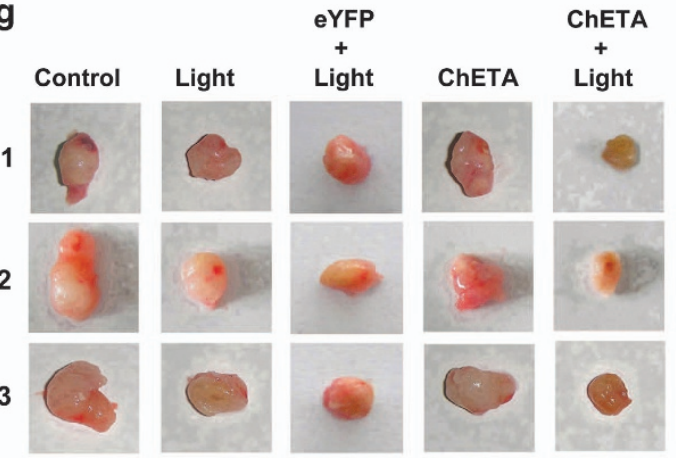

h

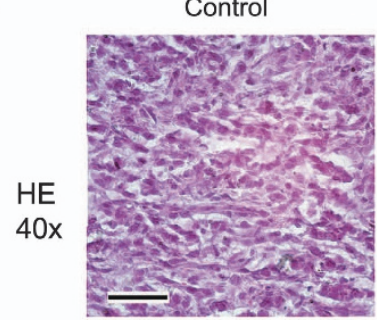

i

CyclinD

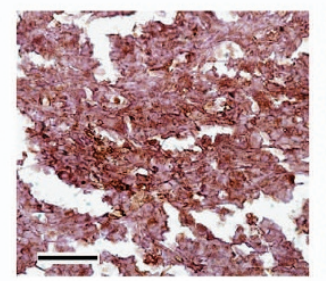

Light
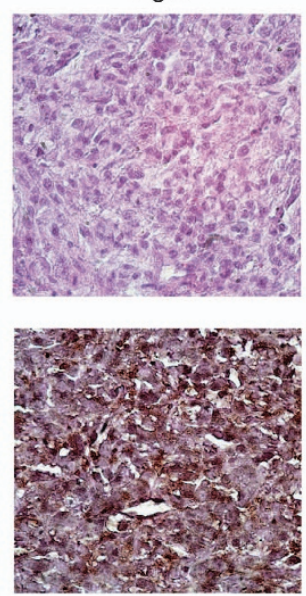

eYFP+Light
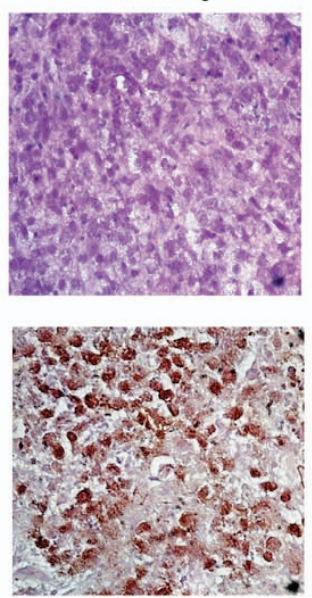
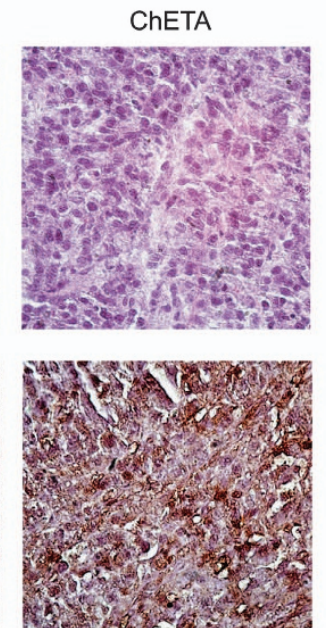

ChETA+Light
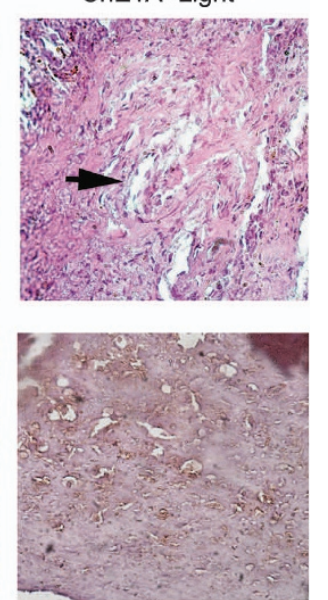

Figure 5 Light stimulation inhibited growth of subcutaneous glioma in mice. (a) Schematic flowchart of the subcutaneous glioma experiment. (b) HE staining (top panel) and immunofluorescence staining of GFAP (bottom panel) of the subcutaneous glioma sections. (c) In vivo expression of ChETA is shown in green fluorescence; no fluorescence is observed in the control group (top panels). Bar $=50 \mu \mathrm{m}$. The percentages of the ChETA-positive glioma cells in the ChETA and control groups are shown in the bottom panel, $n=3$. (d) Schematic drawing of the arrangement of the light-illuminating device and the tumor. Inlet: the blue LED. (e) The subcutaneous glioma was illuminated by light after the mouse was anesthetized. (f) The changes of tumor volume from 1 to 6 weeks post implantation of glioma cells in the control, light, eYFP + light, ChETA, and ChETA + light groups. (g) Excised tumors of the control, light, eYFP + light, ChETA, and ChETA + light groups $(n=3$ in each group) 2 weeks after the light illumination. (h) HE staining of the subcutaneous glioma in the control, light, eYFP + light, ChETA, and ChETA + light groups; necrotic foci were observed in the ChETA + light group (arrow). Bar $=50 \mu \mathrm{m}$. (i) Immunostaining of cyclin D1 in the control, light, eYFP + light, ChETA, and ChETA + light group. Bars $=50 \mu \mathrm{m}$. ${ }^{* *} P<0.01$; ${ }^{* * \star} P<0.001$. The experiments were repeated for three times with similar results 


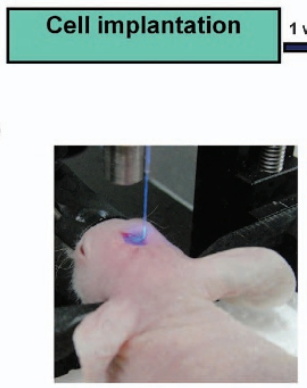

1 wk Light stimulation

C

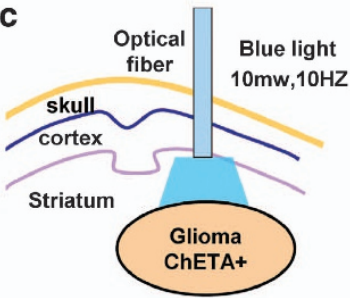

e
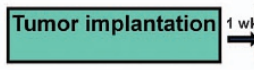

f

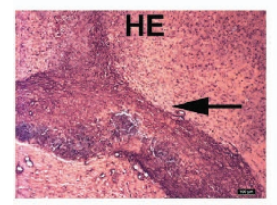
g
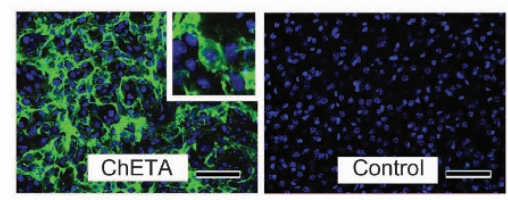

d
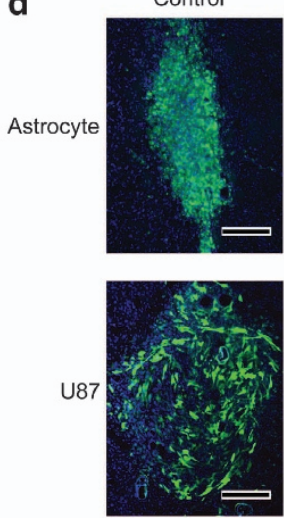

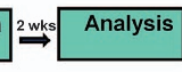

Analysis
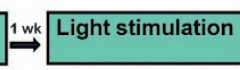

ChETA+Light
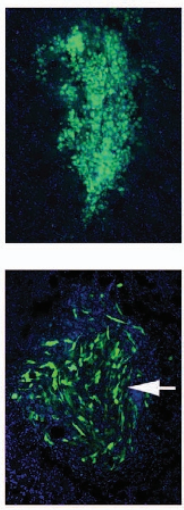
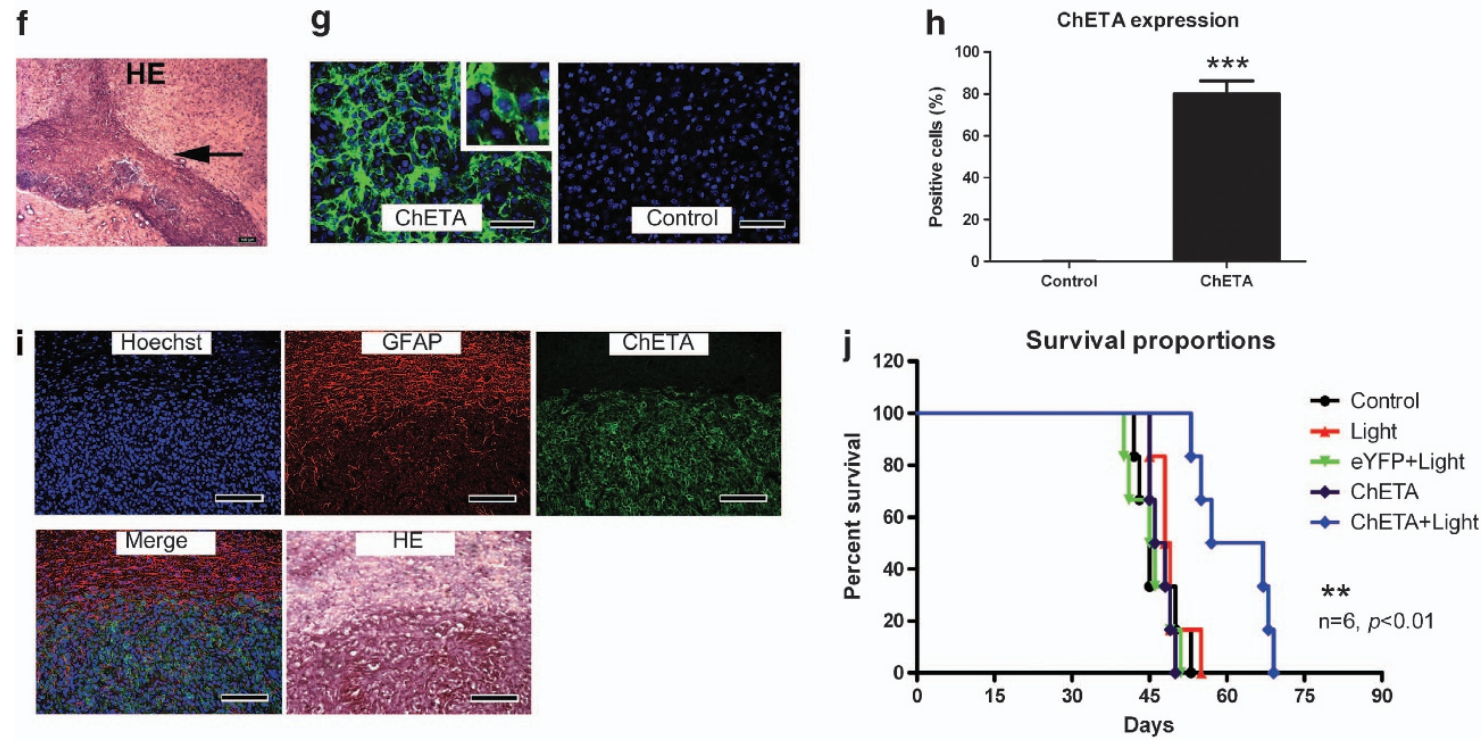

k

Control
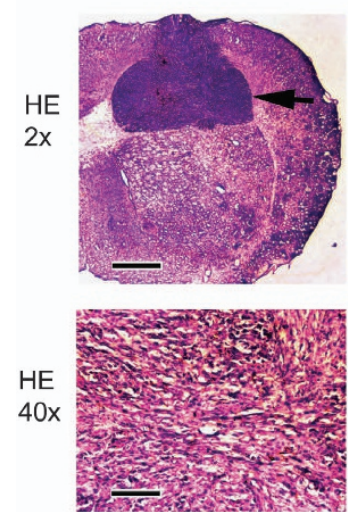

Light
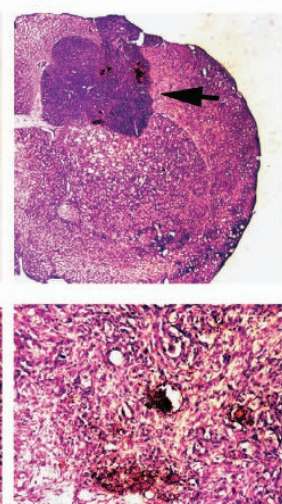

eYFP+Light
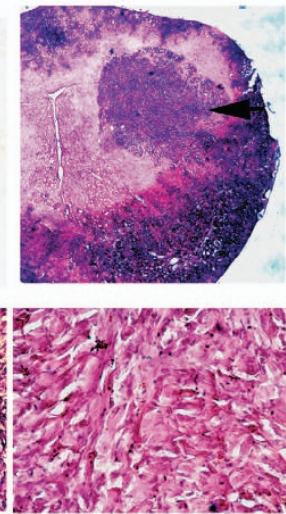

ChEtA
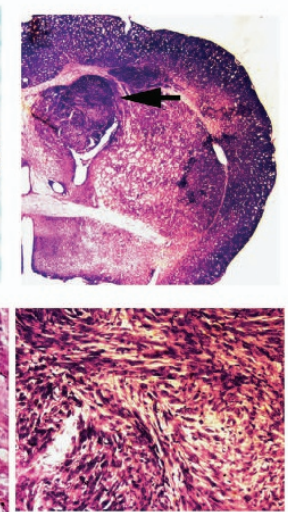

ChETA+Light
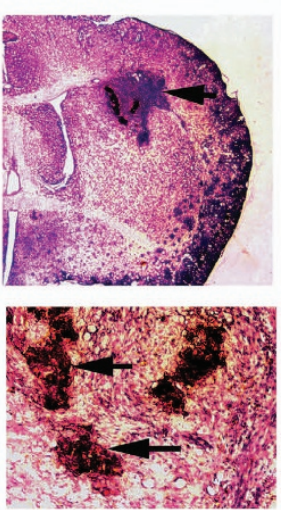

Figure 6 Light stimulation inhibited intracranial glioma growth in mice. (a) Schematic flowchart of the experiment of transplanting ChETA-transfected astrocytes or U87 glioma cells. (b) The intracranial transplantation region was illuminated by blue light after the mice were anesthetized. (c) Schematic drawing of illumination of intracranial glioma using blue light-emitting optical fiber. (d) The green-fluorescence distribution of transplanted astrocytes or U87 glioma cells in control group and ChETA + light group (arrow) at 1 week after the light stimulation. $\mathrm{Bar}=50 \mu \mathrm{m}$. (e) Schematic flowchart of the experiment of intracranial virus injection and light stimulation. (f) $\mathrm{HE}$ staining of the intracranial glioma 7 days post-U87 cell implantation. Bar $=100 \mu \mathrm{m}$. (g) In situ expression of ChETA (green fluorescence) 7 days after injection of the virus into intracranial glioma. No fluorescence was observed in the control group. Bar $=50 \mu \mathrm{m}$. (h) The percentage of the ChETA-positive glioma cells in ChETA and control groups, $n=3$. (i) GFAP immunofluorescence, ChETA expression, and $\mathrm{HE}$ staining of intracranial glioma sections 7 days post-virus injection. ChETA expression (green) was restricted to the tumor region; no green fluorescence was observed in the region outside the tumor. Bar $=100 \mu \mathrm{m}$. (j) Mouse survival curves were plotted for the control, light, eYFP + light, ChETA, and ChETA + light groups. $n=6$ in each group. (k) HE staining of the intracranial glioma (arrow) in the control, light, eYFP + light, ChETA, and ChETA + light groups 2 weeks after the blue light illumination. High magnification $(\mathrm{HE} \times 40)$ showed the disorganized histological appearance, decreased glioma cell density, and necrotic foci (arrow) in the ChETA + light group. Bars $=1 \mathrm{~mm}$ $(\mathrm{K}, \mathrm{HE} \times 2) ; 50 \mu \mathrm{m}(\mathrm{K}, \mathrm{HE} \times 40) .{ }^{* \star} P<0.01 ;{ }^{\star \star *} P<0.001$. The experiments were repeated for three times with similar results 
a

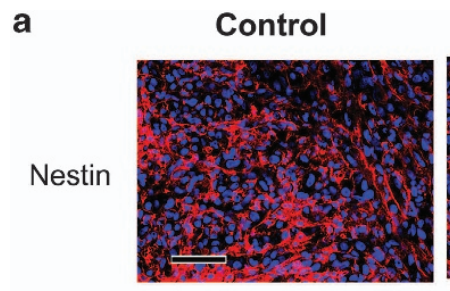

b

EdU

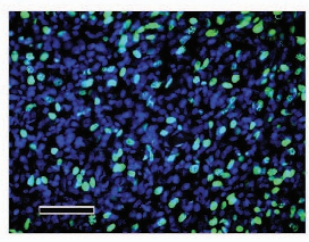

c

CyclinD

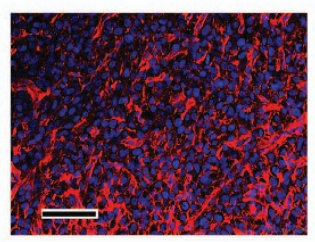

d
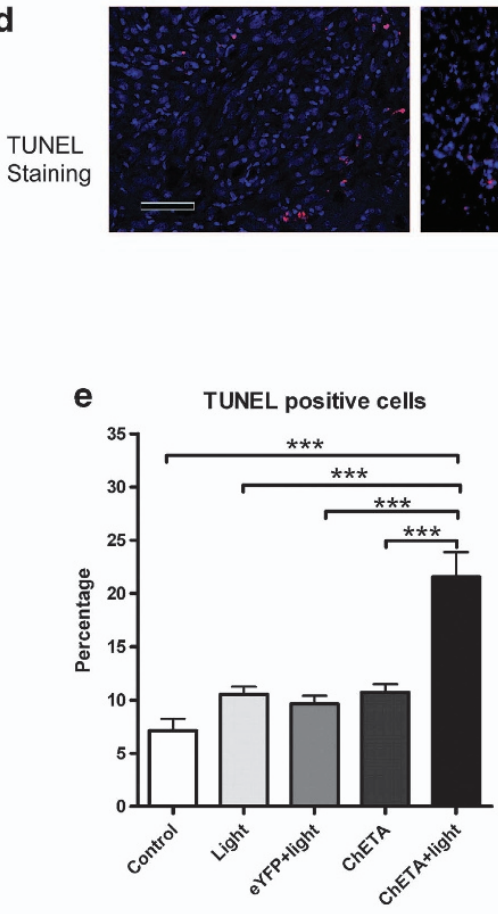

Light
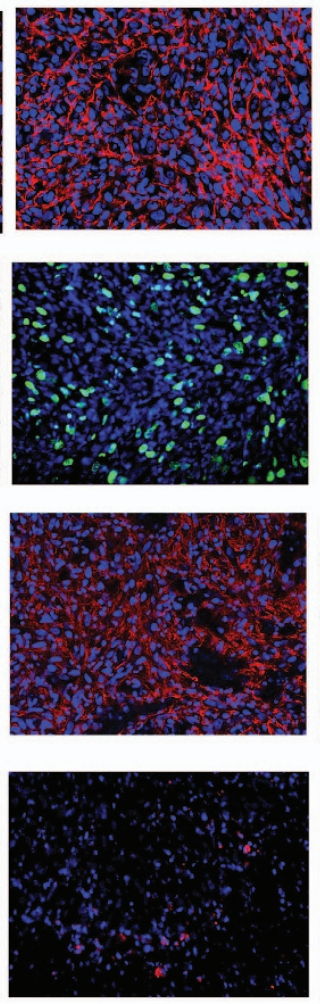

eYFP+Light
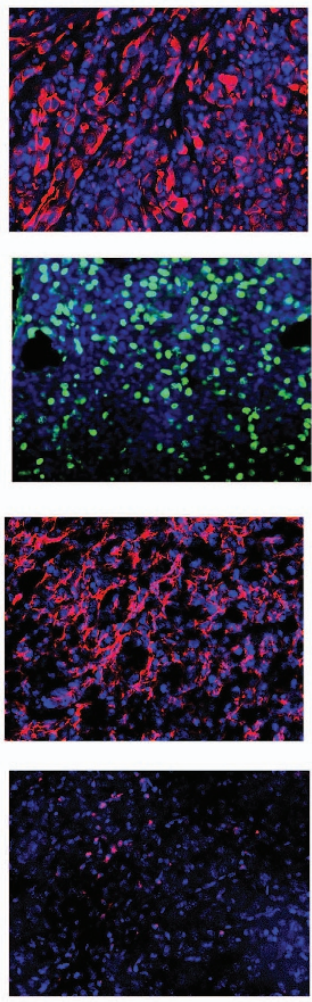

ChETA
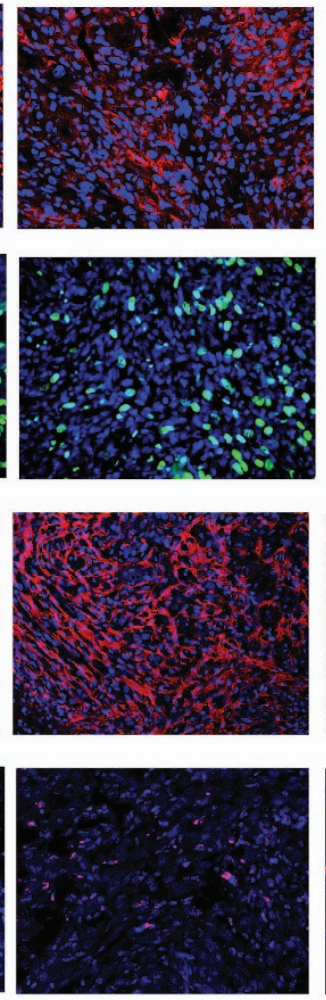

\section{ChETA+Light}
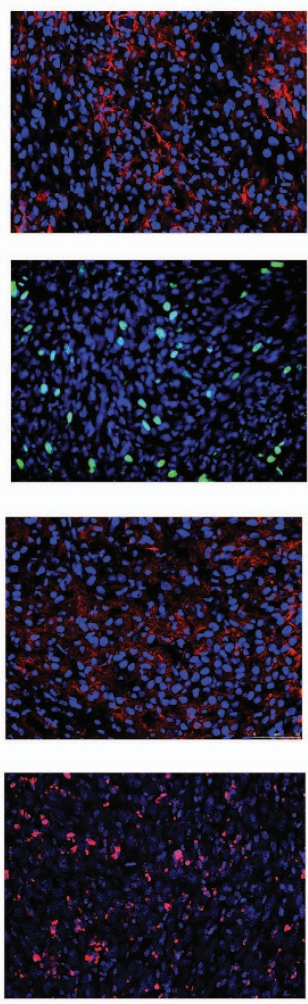

f

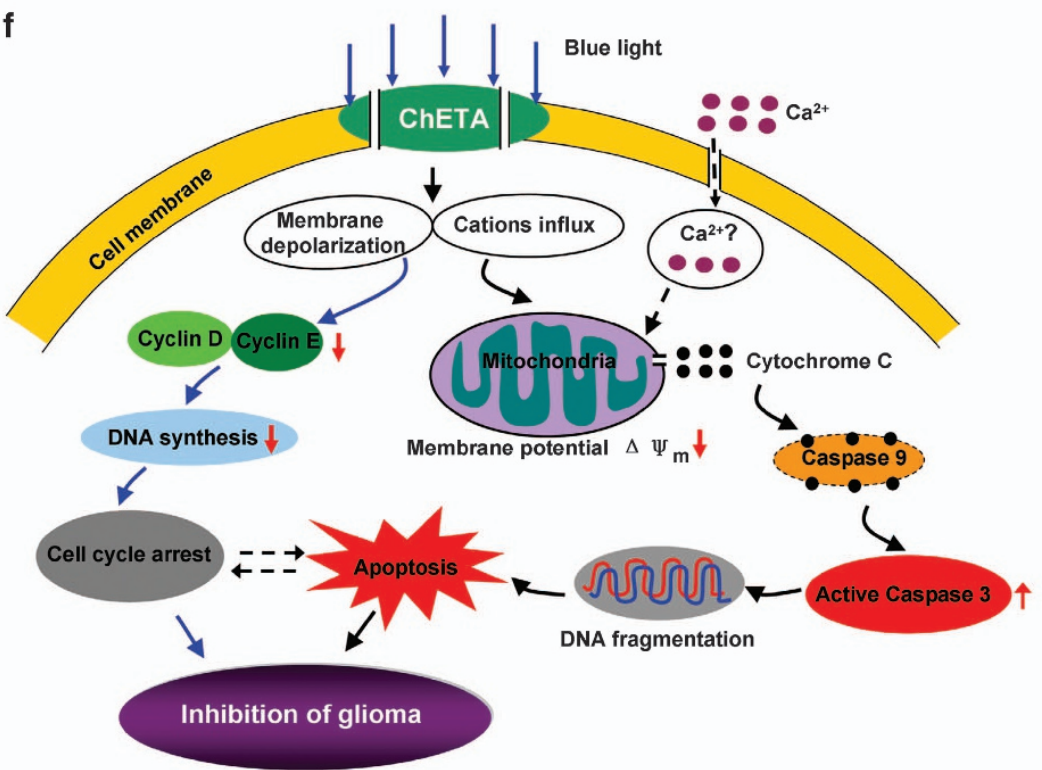

Figure 7 Light stimulation inhibited the proliferation and induced the apoptosis of human glioma cells in vivo. (a) Immunostaining of nestin in the control, light, eYFP + light, ChETA, and ChETA + light groups. (b) EdU-positive cells (green) were observed in the control, light, eYFP + light, ChETA, and ChETA + light groups. Hoechst 33342-stained nuclei are shown in blue. (c) Immunostaining of cyclin D in the control, light, eYFP + light, ChETA, and ChETA + light groups. (d) TUNEL staining of apoptotic U87 cells in the control, light, eYFP + light, ChETA, and ChETA + light groups; Hoechst 33342-stained nuclei are shown in blue. (e) Quantification of the TUNEL-positive cells in the control, light, eYFP + light, ChETA, and ChETA + light groups. (f) Schematic drawing for the mechanism of the light-induced regulation of glioma cell proliferation and apoptosis. Bar $=50 \mu \mathrm{m}(\mathbf{a}-\mathbf{d}) .{ }^{* \star *} P<0.001$. The experiments were repeated for three times with similar results

apoptotic cells in the ChETA + light group consistently argue that intracranial light stimulation effectively inhibits the proliferation and induces apoptosis of human glioma cells.

\section{Discussion}

To our knowledge, our study is the first use of optogenetics to inhibit MG growth both in vitro and in vivo. We have demonstrated, for the first time, that the proliferation, 
apoptosis, and in vivo growth of human MG could be precisely controlled in a light-dependent- and tissue-specific manner. Our data demonstrated that light-induced membrane depolarization and ion channel activity changes could reduce human MG cell viability, disturb cell cycle progression, induce the mitochondria-mediated apoptosis, and effectively inhibit in vivo tumor growth in the established subcutaneous/ intracranial glioma models.

Activities of ion channels and membrane polarization changes have been demonstrated to be important for controlling glioma growth, proliferation, and migration. ${ }^{5,34}$ Blockage of the CIC3 channel, an anion channel for chloride, could inhibit DNA condensation and glioma cell division. ${ }^{8}$ Inhibition of transient receptor potential canonical (TRPC6) channel activity suppressed cell growth and enhanced the antiproliferative effect of ionizing radiation. ${ }^{6}$ Compared with the ion channel antagonists, optogenetics offers a new tool to precisely control the membrane depolarization in a light-controllable and tissuespecific manner. ${ }^{35}$ In our study, ChETA expression could be selectively targeted to the glioma cells using specific promoters; light stimulation could also be precisely manipulated to decrease the viability of glioma cells. Our study thus provides a new approach to target and regulate the function of glioma cells both in vitro and in vivo, using the combination of specific ChETA expression and controlled light illumination.

The significantly decreased viability of human glioma cells compared with astrocytes or neurons (Figure 1) after the light illumination suggests that the light-induced ion influx and membrane depolarization selectively influence the physiological activities of glioma cells. Previous studies have shown that glioma cells and primary astrocytes responded differentially to dexamethasones; ${ }^{36}$ specific cation channel conductance was needed to regulate the glioma cell cycle progression, ${ }^{37}$ suggesting that the physiological function of normal astrocytes or glioma was differentially regulated by the ion channels and downstream cell signaling pathways. ${ }^{38}$ Our study supported these findings and further showed that the apoptosis of astrocytes or glioma cells was differentially influenced by the light-induced membrane depolarization. Optogenetics thus provided a selective approach to regulate the glioma cell membrane properties and induced the apoptosis of human glioma cells, although not simultaneously influencing the apoptosis of normal brain cells.

The mitochondria-mediated apoptosis pathway has been shown to mediate glioma cell death, ${ }^{39}$ and the knockdown of cyclin D1 could inhibit the proliferation and induce apoptosis of human glioblastoma cells. ${ }^{40}$ Here in our study, we demonstrated that the decreased glioma viability was caused by both increased glioma cell death and decreased glioma cell proliferation (Figure 7f). After the light stimulation induced membrane depolarization and cation influx of the glioma cells, the decreased percentage of Edu-labeled dividing cells and downregulated expression of cyclins confirmed the inhibited proliferation of glioma cells (Figure 3). The decreased mitochondrial membrane potential, increased cytosolic cytochrome $c$ release, and increased human active Caspase- 3 supported that the mitochondrial-mediated pathway was activated during glioma cell death (Figure 4). Taken together, our data demonstrated that the continuous depolarization by light illumination could decrease in vitro glioma cell viability, mainly through inhibiting the glioma cell proliferation and inducing the mitochondria-mediated apoptosis (Figure 7f).

Intracranial light stimulation efficiently decreased the number of the transplanted ChETA-transfected glioma cells (but not transplanted astrocytes), suggesting that we could use optogenetics to selectively target in situ glioma growth. The decreased subcutaneous/intracranial tumor size and the prolonged survival time demonstrated that the light illumination had effectively inhibited the in vivo growth of the glioma. Further analysis showed that light stimulation significantly inhibited the expression of cyclins, decreased the number of dividing cells, and increased the number of apoptotic glioma cells, which contributed to the inhibition of the intracranial glioma growth after the light stimulation. The selective ChETA expression in the glioma tissue, along with the lightcontrollable apoptosis of glioma cells, suggested that we could selectively induce glioma death in a light-controllableand tissue-specific manner. Our study thus provided a systemic in vivo approach to decide 'where' and 'when' to induce the glioma cell death, which will be potentially helpful to study the mechanism of glioma cell death in vivo at different stages of neoplastic progression.

The detailed functional changes of ion channels and intracellular pathways influenced by optogenetics may need further study, which will be helpful to the in-depth understanding of the molecular mechanism of light-induced glioma death. By precisely controlling the light illumination parameters (light intensity and frequency), the influence of precisely regulating membrane properties on glioma physiology and downstream signaling pathways could be explored in more details in the future.

In conclusion, the current study demonstrates for the first time that optogenetics, an important technology used to dissect neural circuits, ${ }^{41}$ could also be used as a novel approach for inhibiting MG cell proliferation and inducing glioma cell apoptosis. Therefore, manipulating the glioma cell membrane depolarization using optogenetics could help to understand the biological function of glioma cell membrane depolarization, regulate the physiological activities of human MG, and provide new insights into the glioma biology. ${ }^{42}$

\section{Materials and Methods}

In vitro culture of glioma cell line and primary human glioma cells. U87 and H4 human glioma cell lines were used in the current study, and the experiments were approved by the Research Committee of the Shenzhen Institutes of Advanced Technology, Chinese Academy of Sciences. Culture of the U87 and $\mathrm{H} 4$ cell lines was conducted as described previously. ${ }^{6}$ The isolation and culture of rat-derived astrocytes, microglia, and endothelial cells were conducted as described previously. ${ }^{43-45}$ For the culturing of primary isolated human glioma or non-glioma cells, human brain tissues located within the temporal or frontal lobe were surgically removed at the Beijing Sanbo Brain Hospital. Each glioma was histologically graded by the hospital pathology department based on the World Health Organization grading system. The specimens were collected with the consent of each patient and the hospital's ethics committee. In brief, the tissue pieces were minced and digested with $0.25 \%$ trypsin (Gibco, Carlsbad, CA, USA) for $30 \mathrm{~min}$. The supernatant was filtered and plated in $75-\mathrm{cm}^{2}$ flasks and cultured with DMEM supplemented with $10 \%$ fetal bovine serum and $1 \%$ antibiotics (10000 U of penicillin and streptomycin) for 7 days. Once the cells reached confluence, they were passaged and used in the experiments.

Cell viability assay. Cell viability was analyzed using the MTT-based cytotoxicity assay (Sigma-Aldrich, St. Louis, MO, USA). Neurons, astrocytes, and human glioma cells were seeded into 96-well plates, and light-stimulation-induced 
cytotoxicity was measured. In brief, $20 \mu \mathrm{l}$ of $5 \mathrm{mg} / \mathrm{ml}$ MTT solution was added to each well of the different groups; the culture plates were incubated at $37^{\circ} \mathrm{C}$ for $3.5 \mathrm{~h}$ and the media were carefully removed. Images of the different groups were taken at this stage using a microscope (ECLIPSE 50i, Nikon, Melville, NY, USA) to reflect viable cell density. For quantification, MTT solvent (dimethylsulfoxide) was added to each well and the culture plates were shaken for $15 \mathrm{~min}$. Absorbance at $590 \mathrm{~nm}$ was determined using a microplate reader (Synergy 4, BioTek, Winooski, VT, USA) as a measure of cell viability. Cell viability was normalized to the control group and compared among the groups.

Cell cycle analysis and mitochondrial transmembrane potential detection using flow cytometry. The cell cycle of the glioma cells was determined using a flow cytometer (Cell Lab Quanta SC, Beckman Coulter, Brea, CA, USA). In brief, U87 glioma cells from the different groups were trypsinized, washed with PBS, and fixed with $70 \%$ ice-cold ethanol. Cell pellets were obtained after centrifugation and washed again with PBS. Cells were incubated with PI staining buffer $\left(10 \mu \mathrm{g} / \mathrm{ml} \mathrm{PI}, 100 \mu \mathrm{g} / \mathrm{ml} \mathrm{RNaseA}\right.$, and $0.1 \%$ TritonX-100) at $37^{\circ} \mathrm{C}$ for $30 \mathrm{~min}$. The cell cycle was then analyzed, and the data were acquired using Cell Lab Quanta SC software (Beckman Coulter).

Mitochondrial Transmembrane Potential Apoptosis Detection Kit (Abcam, Cambridge, MA, USA) was used to detect the changes in the mitochondrial transmembrane potential of healthy and apoptotic cells. Briefly, the cationic dye was diluted and incubated with glioma cells from different groups for $20 \mathrm{~min}$, and then the cells were analyzed using flow cytometry. Cationic dyes aggregated in healthy cells are detectable in PI channel showing red fluorescence. We used the percentage of red-fluorescent cells in the total cells to represent the percentage of healthy cells with normal transmembrane potential $\left(\Delta \psi_{\mathrm{m}}\right)$.

EdU incorporation analysis for cell proliferation. The EdU incorporation analysis was performed using a Click-iT Alexa Fluor 488 EdU Imaging Kit (Invitrogen, Carlsbad, CA, USA). In brief, after 24-h incubation with $10 \mu \mathrm{M} \mathrm{EdU}$, the cells were fixed with $4 \%$ paraformaldehyde (PFA) for $15 \mathrm{~min}$ and $0.5 \%$ Triton X-100 was used to permeabilize the cells. The cells were washed twice with $3 \%$ BSA in PBS and then incubated with the Click-iT reaction cocktail (Click-iT reaction buffer, $\mathrm{CuSO}_{4}$, Alexa Fluor 488 Azide, and reaction buffer additive) for $30 \mathrm{~min}$ while being protected from light. The cells were then incubated with Hoechst 33342 to stain the nuclei, and images were acquired. Eight images from each group were selected; the EdU-positive and Hoechst-labeled cells were counted using Image-Pro Plus software (Media Cybernetics Inc, Rockville, MD, USA). The number of EdU-positive cells was normalized to the Hoechst-labeled cells to determine the ratio of EdU-positive cells in the five groups. For the in vivo experiments, EdU $(0.3 \mathrm{mg}$ per $10 \mathrm{~g})$ was intraperitoneally injected into the tumorbearing nude mice $3 \mathrm{~h}$ before killing. The experiments were repeated three times for accuracy and the differences among the groups were compared.

Western blotting. Human glioma cells were lysed and the protein was extracted using lysis buffer (NE-PER Nuclear and Cytoplasmic Extraction Reagents, Pierce/Thermo Fisher Scientific, Waltham, MA, USA). Total proteins were determined using a Bicinchoninic Acid Protein Assay Kit (Pierce/Thermo Fisher Scientific) and denatured using the standard method. The samples were loaded onto $10 \%$ sodium dodecyl sulfate-polyacrylamide gel electrophoresis separating gel and run at a constant voltage of $120 \mathrm{~V}$ for $2.5 \mathrm{~h}$. Transblotting was performed at a constant voltage of $30 \mathrm{~V}$ overnight at $4{ }^{\circ} \mathrm{C}$. The total cyclin D1 and cyclin $\mathrm{E}$ contents were quantitated using mouse anti-human cyclin D1 and mouse anti-human cyclin E antibodies, respectively (Cell Signaling Technology, Beverly, MA, USA), followed by horseradish peroxidase-conjugated goat anti-mouse IgG (Sigma). Color development was achieved by using the ECL Western Blotting Detection Kit (Pierce/Thermo Fisher Scientific). The band density was assessed for the different groups and normalized to $\beta$-actin using Image $\mathrm{J}$ software (version 1.43; National Institutes of Health). The expression level difference of cyclin D1 and cyclin $\mathrm{E}$ was compared among the groups.

Quantitative determination of human active caspase-3 and cytochrome $\boldsymbol{c}$. The concentrations of human active Caspase-3 in cell extracts were determined using Human active Caspase-3 Immunoassay Kit (R\&D Systems, Minneapolis, MN, USA). The concentrations of human cytosolic cytochrome $c$ were determined using Human Cytochrome $c$ Kit (R\&D Systems). All the experiments were carried out according to the manufacturers' instructions. The optical density was determined at $450 \mathrm{~nm}$ using the microplate reader (Synergy 4,
BioTek). The concentrations of active Caspase-3 and cytosolic cytochrome $c$ were determined, normalized to the control group, and compared among the different groups.

Immunostaining and in situ cell apoptosis detection. Human glioma cells were fixed with 4\% PFA and incubated with rabbit antibody to glial fibrillary acidic protein (GFAP) (Abcam) and mouse antibody to nestin (Abcam) to characterize the cultured glioma cell phenotype. After being washed three times, the slides were incubated with fluorescein isothiocyanate or phycoerythrinconjugated goat anti-rabbit or anti-mouse secondary antibodies (Invitrogen), respectively. The slides were counterstained with Hoechst 33342 to stain the nuclei and were then mounted.

Tissue sections were deparaffinized, rehydrated, and blocked by goat serum. The sections were then incubated with primary rabbit anti-GFAP antibody, mouse antibody to nestin (Abcam), and mouse anti-cyclin D1 antibody (10 $\mu \mathrm{g} / \mathrm{ml})$. The sections were washed and labeled with fluorescent secondary antibody, or the detection was accomplished by using a rabbit or mouse Vectastain Elite ABC Kit (Vector, Burlingame, CA, USA) with diaminobenzidine as the chromogen. The sections were counterstained with hematoxylin or Hoechst 33342 and then mounted for image acquisition. The percentage Nestin/Edu-positive cells in the different groups was calculated and compared.

In Situ Cell Death Detection Kit (Roche, Basel, Switzerland) was used to detect and quantify apoptotic cell death in glioma cells and tissues, based on the TUNEL technology. All the experiments were carried out according to the manufacturers' instructions. The percentage of TUNEL-positive cells in the different groups was calculated and compared.

Tissue processing and histological staining. For the subcutaneous glioma model, the tumor samples were fixed in $4 \%$ PFA at $4{ }^{\circ} \mathrm{C}$ and dehydrated using gradient ethanol. After xylene treatment, the samples were embedded in paraffin and sectioned at 5- $\mu \mathrm{m}$ thickness. For the intracranial glioma model, the brains were fixed in $4 \%$ PFA at $4{ }^{\circ} \mathrm{C}$ overnight and cryosectioned at $20 \mu \mathrm{m}$ per slice. HE staining was performed on the tissue sections, and images were taken under the microscope (ECLIPSE 50i; Nikon).

ChETA expression in human glioma cells using lentiviral vectors. Lentiviral vectors carrying the ChETA-eYFP or eYFP gene (Figure 1a) were constructed. Briefly, the CMV or $c$-fos promoter was cloned into the pLenti-CaMK-a-ChETA-eYFP or pLenti-CaMK-a-eYFP plasmid (provided by Dr. Karl Deisseroth in Stanford University):;1 a high titer lentivirus was produced via calcium phosphate co-transfection of 293FT cells with the lentiviral vector pCMV $\Delta$ R8.74 and pMD2G. Twenty-four hours after the transfection, 293FT cells were transferred to a serum-free medium containing $5 \mathrm{mM}$ sodium butyrate; the supernatant was collected $16 \mathrm{~h}$ later and concentrated using ultracentrifugation at $50000 \times g$ with a $20 \%$ sucrose cushion. PBS was used to re-suspend the viral pellets before use.

Lentivirus was used to express the ChETA fusion protein in cultured cells. The neurons, astrocytes, glioma cell line, and primary human glioma cells were incubated with the lentivirus $\left(10^{9} \mathrm{TU} / \mathrm{ml}\right)$ in a serum-free medium for 48 and $120 \mathrm{~h}$, respectively. ChETA expression was confirmed by observation of green fluorescence under the microscope. For quantification of the ChETA-positive cells in the subcutaneous/intracranial glioma tissue, three mice in control and ChETA group were used and the ChETA-positive cells were counted and summed up from 10 tissue sections separately. The number of ChETA-positive cells was expressed as a percentage of the total Hoechst-positive cells.

In vitro stimulation of ChETA-expressing glioma cells using blue light with a wavelength of $460-485 \mathrm{~nm}$. We constructed a homemade LED to stimulate the ChETA-expressing glioma cells for $1 \mathrm{~h}(10 \mathrm{~Hz}$ and 50-ms stimulus intervals). The arrangement of the lamps and plate well is schematically illustrated (Figure 1c), and the average output power of the LED was $1.64 \mathrm{~mW} / \mathrm{mm}^{2}$. The glioma cells were plated in 96- or 6-well plates and were divided into five groups: control group without ChETA expression and light stimulation; light group, which was stimulated by light but had no ChETA or eYFP expression; eYFP + light group, which expressed eYFP and was stimulated by light; ChETA group, which expressed ChETA but without light stimulation; and ChETA + light group, which expressed ChETA and was stimulated with blue light. At $24 \mathrm{~h}$ after the light stimulation, the cells from different groups were harvested and examined using cell viability and other analyses. 
Subcutaneous glioma animal model and in vivo light stimulation. All animal experimental protocols were approved by the Research Committee of the Shenzhen Institutes of Advanced Technology. Fifty female athymic nude mice (4-6 weeks of age) were used in the subcutaneous glioma model. The mice were divided into five groups: control, light, eYFP + light, ChETA, and ChETA + light. The mice were injected subcutaneously with $1 \times 10^{7} \mathrm{U} 87$ cells in $100 \mu \mathrm{l}$ Dulbecco's Modified Eagle Medium (DMEM) on the flank region to establish the tumor model. Tumor lengths and widths were measured every week after tumor implantation, and tumor volume was calculated using the following formula: volume $=\left(\right.$ length $\times$ width $\left.^{2}\right) / 2$.

At 1 week after the implantation, $10 \mu \mathrm{l}$ ChETA or eYFP lentivirus vectors $\left(10^{9} \mathrm{TU} / \mathrm{ml}\right)$ were injected intratumorally into the ChETA, ChETA + light, and eYFP + light groups. One week after virus injection, we constructed a blue LED (Figure $5 d$ ) to illuminate for $30 \mathrm{~min}$ the subcutaneous tumors of the light, eYFP + light, and ChETA + light groups (Figure 5e). The distance between the lamp and the skin was $\sim 1.5 \mathrm{~mm}$, whereas the average power was $1.7 \mathrm{~mW} / \mathrm{mm}^{2}$. Two weeks after illumination, the mice were killed by cervical dislocation and the tumors were biopsied for tissue processing.

Intracranial glioma model and in vivo light stimulation. All animal experimental protocols were approved by the Research Committee of the Shenzhen Institutes of Advanced Technology. Eighty female athymic nude mice (4-6 weeks old) were used in the intracranial glioma model. The mice were divided into the following five groups: control, light, eYFP + light, ChETA, and ChETA + light groups. The mice were anesthetized with an intraperitoneal injection of phenobarbitol sodium $(100 \mathrm{mg} / \mathrm{kg})$. The head skin was cleaned with a $70 \%$ isopropanol solution and an incision was made along the midline. For cell implantation, a burr hole with a diameter of $1 \mathrm{~mm}$ was drilled $1.0 \mathrm{~mm}$ anterior to the bregma and $2.0 \mathrm{~mm}$ right to the midline. U87 cells or rat brain-derived astrocytes $\left(2 \times 10^{5}\right)$ were suspended in $5 \mu \mathrm{l}$ DMEM medium and were injected using a $10-\mu \mathrm{l}$ Hamilton syringe (31 gauge needle) to a depth of $3 \mathrm{~mm}$ at a speed of $1 \mu \mathrm{l} / \mathrm{min}$

One week after intracranial implantation of the glioma cells, $3 \mu$ l lentivirus solution $\left(10^{9} \mathrm{TU} / \mathrm{ml}\right)$ containing ChETA or eYFP vectors was injected into the glioma tissue in the ChETA, ChETA + light, and eYFP + light groups, respectively. No virus was injected into the control or light groups. One week after virus injection, we used a blue light-emitting optical fiber with a diameter of $200 \mu \mathrm{m}$ to illuminate the intracranial tumor for $30 \mathrm{~min}$ in the light, eYFP + light, and ChETA + light groups (Figure $6 \mathrm{~b}$ ). The distance between the optical fiber tip and the cell implantation position was $\sim 100 \mu \mathrm{m}$, and the average output power was $\sim 10 \mathrm{~mW} / \mathrm{mm}^{2}$. Two weeks after the light stimulation, the mice were perfused with 4\% PFA and the brain tissue was removed for histological analysis and immunostaining.

Electrophysiology. Using standard whole-cell patch-clamp techniques, we acquired whole-cell recordings of glioma cell line U87 and primary human glioma cells. Using a puller (P-2000; Sutter Instruments, Novato, CA, USA), patch pipettes were pulled from thin-walled borosilicate glass (Sutter Instruments) to a resistance of 3-5 M $\Omega$. We used a Multiclamp 700B amplifier (Molecular Devices, Sunnyvale, CA, USA) to acquire cell recordings, and the currents were low-passfiltered at $1 \mathrm{KHz}$ and digitalized at $10 \mathrm{KHz}$ using a Digidata $1440 \mathrm{~A}$ (Molecular Devices). The standard $\mathrm{KCl}$ pipette solution used contained the following salts: $140 \mathrm{mM} \mathrm{KCl}, 4.3 \mathrm{mM} \mathrm{MgCl}$, $11 \mathrm{mM}$ EGTA, $4.4 \mathrm{mM} \mathrm{Na} 2 \mathrm{ATP}$, and $10 \mathrm{mM}$ 4-(2hydroxyethyl)-1-piperazineethanesulfonic acid (HEPES) sodium salt; the $\mathrm{pH}$ was adjusted to 7.2 using Tris base. Osmolarity was adjusted to $302 \mathrm{mOsm} / \mathrm{kg}$. Normal extracellular $\mathrm{NaCl}$ bath solution contained the following salts: $150 \mathrm{mM} \mathrm{NaCl}, 5 \mathrm{mM}$ $\mathrm{KCl}, 3.31 \mathrm{mM} \mathrm{CaCl}_{2}, 10 \mathrm{mM}$ glucose, and 10 HEPES acid. The $\mathrm{pH}$ was adjusted to 7.4 and the osmolarity was $306-312 \mathrm{mOsm} / \mathrm{kg}$. Data were acquired and stored with the use of pClamp 10 (Molecular Devices). Current subtractions and currentvoltage relationships from electrophysiological recordings were determined using Clampfit (Molecular Devices).

A DG-4 high-speed optical switch with a 300 W xenon lamp (Sutter Instruments) was used to deliver the light pulses for the ChETA activation. The output power was 3-5 $\mathrm{mW}$. We used $10-\mathrm{Hz}$ light stimulation $(1-500 \mathrm{~ms})$. The interval for the paired stimulation was $25-500 \mathrm{~ms}$. The whole-cell recording of the light-evoked photocurrents was also acquired for a 2-s period before and after $1 \mathrm{~h}$ of light stimulation.

Statistical analyses. Data are expressed as the mean \pm S.E.M. of the number of tests stated. The significance of cell viability differences among the different groups was tested using analysis of variance (ANOVA). Bonferroni's multiple comparison test was used as a post hoc test. The ratio of EdU-positive cells, ChETA-positive cells, Nestin/TUNEL-positive cells, the cyclin D1 and cyclin E expression levels, caspase 3 and cytochrome $c$ levels among the different groups were tested using one-way ANOVA. Bonferroni's multiple comparison test was used as a post hoc test. Tumor volume differences among the different groups were tested by one-way ANOVA. Bonferroni's multiple comparison test was used as a post hoc test. The log-rank test was performed to test the significance of the survival time differences among different groups. All of the statistical tests were performed using the Statview (Version 10.0; SPSS, Chicago, IL, USA) program package or GraphPad Prism software (Version 5.0; La Jolla, CA, USA). A P-value $<0.05$ was considered statistically significant.

\section{Conflict of Interest}

The authors declare no conflict of interest

Acknowledgements. We thank Dr. Karl Deisseroth (Stanford University) for providing the ChETA plasmid. This research project was partially sponsored by the National Basic Research Program of China under grant numbers 2012CB966902 and 2010CB529605; the National Natural Science Foundation of China under grant numbers NSFC 81000551, 81000595, and 91132306; the Instrument Developing Project of the Chinese Academy of Sciences (2010019); Strategic Priority Research Program (B) of the Chinese Academy of Sciences (XDB02050003); 'Hundred Talents Program' of the Chinese Academy of Science, the National Key Technology Research and Development Program of the Ministry of Science and Technology of China (2012BAI01B08); Guangdong Innovation Research Team Fund for Low-cost Healthcare Technologies, Shenzhen Governmental Basic Research Grant JC201006040897A, JC201005270296A, and JC201005270291A.

1. Gladson CL, Prayson RA, Liu WM. The pathobiology of glioma tumors. Annu Rev Pathol 2010; 5: 33-50.

2. Scott JN, Rewcastle NB, Brasher PM, Fulton D, MacKinnon JA, Hamilton M et al. Which glioblastoma multiforme patient will become a long-term survivor? A population-based study. Ann Neurol 1999; 46: 183-188.

3. Van Meir EG, Hadjipanayis CG, Norden AD, Shu HK, Wen PY, Olson JJ. Exciting new advances in neuro-oncology: the avenue to a cure for malignant glioma. CA Cancer J Clin 2010; 60: 166-193.

4. Huse JT, Holland EC. Targeting brain cancer: advances in the molecular pathology of malignant glioma and medulloblastoma. Nat Rev Cancer 2010; 10: 319-331.

5. Sontheimer $\mathrm{H}$. An unexpected role for ion channels in brain tumor metastasis. Exp Biol Med (Maywood) 2008; 233: 779-791.

6. Ding X, He Z, Zhou K, Cheng J, Yao H, Lu D et al. Essential role of TRPC6 channels in G2/M phase transition and development of human glioma. J Natl Cancer Inst 2010; 102: 1052-1068

7. Lee YI, Seo M, Kim Y, Kim SY, Kang UG, Kim YS et al. Membrane depolarization induces the undulating phosphorylation/dephosphorylation of glycogen synthase kinase 3beta, and this dephosphorylation involves protein phosphatases $2 \mathrm{~A}$ and $2 \mathrm{~B}$ in SH-SY5Y human neuroblastoma cells. J Biol Chem 2005; 280: 22044-22052.

8. Habela CW, Olsen ML, Sontheimer $\mathrm{H}$. $\mathrm{ClC} 3$ is a critical regulator of the cell cycle in normal and malignant glial cells. J Neurosci 2008; 28: 9205-9217.

9. Haas BR, Sontheimer H. Inhibition of the sodium-potassium-chloride cotransporter isoform-1 reduces glioma invasion. Cancer Res 2010; 70: 5597-5606.

10. Ghiani CA, Yuan X, Eisen AM, Knutson PL, DePinho RA, McBain CJ et al. Voltageactivated $\mathrm{K}+$ channels and membrane depolarization regulate accumulation of the cyclindependent kinase inhibitors p27(Kip1) and p21(CIP1) in glial progenitor cells. $J$ Neurosci 1999; 19: 5380-5392.

11. Kraft $R$, Krause $P$, Jung $S$, Basrai $D$, Liebmann L, Bolz J et al. BK channel openers inhibit migration of human glioma cells. Pflugers Arch 2003; 446: 248-255

12. Weaver $A K$, Liu $X$, Sontheimer $H$. Role for calcium-activated potassium channels (BK) in growth control of human malignant glioma cells. J Neurosci Res 2004; 78: 224-234.

13. Debska-Vielhaber G, Godlewski MM, Kicinska A, Skalska J, Kulawiak B, Piwonska M et al. Large-conductance $\mathrm{K}+$ channel openers induce death of human glioma cells. $J$ Physiol Pharmacol 2009; 60: 27-36.

14. Deisseroth K. Optogenetics. Nat Methods 2011; 8: 26-29.

15. Nagel G, Szellas T, Huhn W, Kateriya S, Adeishvili N, Berthold P et al. Channelrhodopsin2, a directly light-gated cation-selective membrane channel. Proc Natl Acad Sci USA 2003; 100: $13940-13945$

16. Boyden ES, Zhang F, Bamberg E, Nagel G, Millisecond-timescale Deisseroth K. genetically targeted optical control of neural activity. Nat Neurosci 2005; 8: 1263-1268. 
17. Arenkiel BR, Peca J, Davison IG, Feliciano C, Deisseroth K, Augustine GJ et al. In vivo light-induced activation of neural circuitry in transgenic mice expressing channelrhodopsin-2. Neuron 2007; 54: 205-218.

18. Zhang F, Wang LP, Brauner M, Liewald JF, Kay K, Watzke $\mathrm{N}$ et al. Multimodal fast optical interrogation of neural circuitry. Nature 2007; 446: 633-639.

19. Alilain WJ, Li X, Horn KP, Dhingra R, Dick TE, Herlitze $S$ et al. Light-induced rescue of breathing after spinal cord injury. J Neurosci 2008; 28: 11862-11870.

20. Cardin JA, Carlen M, Meletis K, Knoblich U, Zhang F, Deisseroth $K$ et al. Driving fast-spiking cells induces gamma rhythm and controls sensory responses. Nature 2009; 459: 663-667.

21. Gradinaru V, Mogri M, Thompson KR, Henderson JM, Deisseroth K. Optical deconstruction of parkinsonian neural circuitry. Science 2009; 324: 354-359.

22. Wyart C, Del Bene F, Warp E, Scott EK, Trauner D, Baier H et al. Optogenetic dissection of a behavioural module in the vertebrate spinal cord. Nature 2009; 461: 407-410.

23. Dhawale AK, Hagiwara A, Bhalla US, Murthy VN, Albeanu DF. Non-redundant odor coding by sister mitral cells revealed by light addressable glomeruli in the mouse. Nat Neurosci 2010; 13: 1404-1412.

24. Haubensak W, Kunwar PS, Cai H, Ciocchi S, Wall NR, Ponnusamy R et al. Genetic dissection of an amygdala microcircuit that gates conditioned fear. Nature 2010; 468 270-276.

25. Lobo MK, Covington HE 3rd, Chaudhury D, Friedman AK, Sun H, Damez-Werno D et al. Cell type-specific loss of BDNF signaling mimics optogenetic control of cocaine reward. Science 2010; 330: 385-390.

26. Abbott SB, Stornetta RL, Fortuna MG, Depuy SD, West GH, Harris TE et al. Photostimulation of retrotrapezoid nucleus phox2b-expressing neurons in vivo produces long-lasting activation of breathing in rats. J Neurosci 2009; 29: 5806-5819.

27. Abbott SB, Stornetta RL, Socolovsky CS, West GH, Guyenet PG. Photostimulation of channelrhodopsin-2 expressing ventrolateral medullary neurons increases sympathetic nerve activity and blood pressure in rats. J Physiol 2009; 587(Pt 23): 5613-5631.

28. Kanbar R, Depuy SD, West GH, Stornetta RL, Guyenet PG. Regulation of visceral sympathetic tone by A5 noradrenergic neurons in rodents. J Physiol 2010; 589(Pt 4): 903-917.

29. Airan RD, Thompson KR, Fenno LE, Bernstein H, Deisseroth K. Temporally precise in vivo control of intracellular signalling. Nature 2009; 458: 1025-1029.

30. Gourine AV, Kasymov V, Marina N, Tang F, Figueiredo MF, Lane S et al. Astrocytes control breathing through $\mathrm{pH}$-dependent release of ATP. Science 2010; 329: 571-575.

31. Gunaydin LA, Yizhar O, Berndt A, Sohal VS, Deisseroth K, Hegemann P. Ultrafast optogenetic control. Nat Neurosci 2010; 13: 387-392.

32. Milde-Langosch $\mathrm{K}$. The Fos family of transcription factors and their role in tumourigenesis. Eur J Cancer 2005; 41: 2449-2461.
33. Gottlieb E, Armour SM, Harris MH, Thompson CB. Mitochondrial membrane potential regulates matrix configuration and cytochrome c release during apoptosis. Cell Death Differ 2003; 10: 709-717.

34. Watkins S, Sontheimer H. Hydrodynamic cellular volume changes enable glioma cell invasion. J Neurosci 2011; 31: 17250-17259.

35. Scanziani M, Hausser M. Electrophysiology in the age of light. Nature 2009; 461 930-939.

36. Hinkerohe D, Wolfkuhler D, Haghikia A, Meier C, Faustmann PM, Schlegel U. Dexamethasone differentially regulates functional membrane properties in glioma cell lines and primary astrocytes in vitro. J Neurooncol 2011; 103: 479-489.

37. Rooj AK, McNicholas CM, Bartoszewski R, Bebok Z, Benos DJ, Fuller CM. Glioma-specific cation conductance regulates migration and cell cycle progression. J Biol Chem 2012; 287: 4053-4065.

38. Yang C, lyer RR, Yu AC, Yong RL, Park DM, Weil RJ et al. Beta-Catenin signaling initiates the activation of astrocytes and its dysregulation contributes to the pathogenesis of astrocytomas. Proc Natl Acad Sci USA 2012; 109: 6963-6968.

39. Ordys BB, Launay S, Deighton RF, McCulloch J, Whittle IR. The role of mitochondria in glioma pathophysiology. Mol Neurobiol 2010; 42: 64-75.

40. Wang J, Wang Q, Cui Y, Liu ZY, Zhao W, Wang CL et al. Knockdown of cyclin D1 inhibits proliferation, induces apoptosis, and attenuates the invasive capacity of human glioblastoma cells. J Neurooncol 2012; 106: 473-484.

41. Buchen L. Neuroscience: Illuminating the brain. Nature 2010; 465: 26-28.

42. Hanahan D, Weinberg RA. Hallmarks of cancer: the next generation. Cell 2011; 144 646-674.

43. Cecchelli R, Dehouck B, Descamps L, Fenart L, Buee-Scherrer VV, Duhem C et al. In vitro model for evaluating drug transport across the blood-brain barrier. Adv Drug Deliv Rev 1999; 36: 165-178.

44. Saura J, Tusell JM, Serratosa J. High-yield isolation of murine microglia by mild trypsinization. Glia 2003; 44: 183-189.

45. Higashimori $\mathrm{H}$, Sontheimer H. Role of Kir4.1 channels in growth control of glia. Glia 2007; 55: 1668-1679.

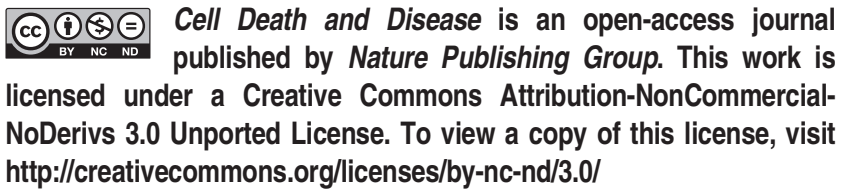

(c) (i) $(-)$ Cell Death and Disease is an open-access journal licensed under a Creative Commons Attribution-NonCommercialNoDerivs 3.0 Unported License. To view a copy of this license, visit http://creativecommons.org/licenses/by-nc-nd/3.0/

Supplementary Information accompanies this paper on Cell Death and Disease website (http://www.nature.com/cddis) 